\title{
Noninvasive measurement of cardiac stroke volume using pulse wave velocity and aortic dimensions: a simulation study
}

\author{
Charles F Babbs
}

Correspondence:

babbs@purdue.edu

Weldon School of Biomedical

Engineering, Purdue University, 206

South Martin Jische Drive, West

Lafayette, Indiana 47907-2032, USA

\begin{abstract}
Background: Concerns about the cost-effectiveness of invasive hemodynamic monitoring in critically ill patients using pulmonary artery catheters motivate a renewed search for effective noninvasive methods to measure stroke volume. This paper explores a new approach based on noninvasively measured pulse wave velocity, pulse contour, and ultrasonically determined aortic cross sectional area.
\end{abstract}

Methods: The Bramwell-Hill equation relating pulse wave velocity to aortic compliance is applied. At the time point on the noninvasively measured pulse contour, denoted $t_{h}$, when pulse amplitude has fallen midway between systolic and diastolic values, the portion of stroke volume remaining in the aorta, and in turn the entire stroke volume, can be estimated from the compliance and the pulse waveform. This approach is tested and refined using a numerical model of the systemic circulation including the effects of blood inertia, nonlinear compliance, aortic tapering, varying heart rate, and varying myocardial contractility, in which noninvasively estimated stroke volumes were compared with known stroke volumes in the model.

Results: The Bramwell-Hill approach correctly allows accurate calculation of known, constant aortic compliance in the numerical model. When nonlinear compliance is present the proposed noninvasive technique overestimates true aortic compliance when pulse pressure is large. However, a reasonable correction for nonlinearity can be derived and applied to restore accuracy for normal and for fast heart rates (correlation coefficient > 0.98).

Conclusions: Accurate estimates of cardiac stroke volume based on pulse wave velocity are theoretically possible and feasible. The precision of the method may be less than desired, owing to the dependence of the final result on the square of measured pulse wave velocity and the first power of ultrasonically measured aortic cross sectional area. However, classical formulas for propagation of random errors suggest that the method may still have sufficient precision for clinical applications. It remains as a challenge for experimentalists to explore further the potential of noninvasive measurement of stroke volume using pulse wave velocity. The technique is non-proprietary and open access in full detail, allowing future users to modify and refine the method as guided by practical experience.

\section{Biomed Central}

(c) 2014 Babbs; licensee BioMed Central Ltd. This is an Open Access article distributed under the terms of the Creative Commons Attribution License (http://creativecommons.org/licenses/by/4.0), which permits unrestricted use, distribution, and reproduction in any medium, provided the original work is properly credited. The Creative Commons Public Domain Dedication waiver (http:// creativecommons.org/publicdomain/zero/1.0/) applies to the data made available in this article, unless otherwise stated. 


\section{Background}

Monitoring cardiac pump function is extremely useful in critical care medicine and has been the standard of care in order to ensure tissue oxygenation [1]. Clinical measurement of cardiac output is traditionally done using a flow-directed Swan-Ganz catheter, placed percutaneously into the pulmonary artery. Typically the pulmonary artery catheter is equipped with an injection port and a downstream temperature sensor to measure total pulmonary artery blood flow by thermodiluiton [2]. In recent years, however, the cost effectiveness of this invasive procedure has been called into question [3-5], especially given complications that occur in about 10 percent of cases [4]. In the SUPPORT trial the 30 day survival critically ill patients was greater in 3552 patients managed without a pulmonary artery catheter than in 2184 similar patients managed with a pulmonary artery catheter [3]. Moreover, in 1008 matched pairs of patients managed either with or without pulmonary artery catheters, the total cost was $38 \%(\$ 13,600)$ greater when pulmonary artery catheters were used to monitor heart function. Hence it is timely to revisit the issue of clinical monitoring of stroke volume and cardiac output with an eye toward less invasive and less expensive options.

According to Geerts, Aarts, and Jansen [6] the ideal technique for the measurement of cardiac output would be one that is accurate, precise, operator independent, fast responding, non-invasive, continuous, easy to use, inexpensive, and safe. The present paper proposes a new technique for measurement of stroke volume and cardiac output by combining standard cuff-based brachial artery blood pressure data, noninvasive measurements of aortic pulse wave velocity [7], and ultrasonic measurements of aortic luminal cross sectional area [8]. The theoretical feasibility of this alternative technique is explored in three stages. The first stage is an analytical description of the underlying theory of the proposed method, including consideration of tapering of the aortic diameter, and axial gradients in local aortic compliance. The second stage is a test of the validity and accuracy of the method using a numerical model of the aorta and systemic circulation to explore effects of potential confounding variables, including simulated atherosclerosis, nonlinear compliance, and fast heart rates. The third stage is a discussion of the precision of the method based on the propagation of errors from the multiple separate measurements required in the calculation of stroke volume and cardiac output.

\section{Theory}

\section{Overview}

A well known clinical rule of thumb is that stroke volume is related directly to arterial pulse pressure (that is, systolic minus diastolic pressure) in a given patient, when aortic compliance is constant. The compliance of an elastic tube is the ratio of volume change $\Delta \mathrm{V}$ to pressure change $\Delta \mathrm{P}$ when an incremental volume $\Delta \mathrm{V}$ is introduced. In symbols $\mathrm{C}=\Delta \mathrm{V} / \Delta \mathrm{P}$. The dynamic compliance is the instantaneous slope of the volume versus pressure curve. For an aorta of given compliance the stroke volume, SV, is related to pulse pressure PP directly: SV C.PP [9-12] if runoff of blood from the aorta is taken into account. Because the compliance is strongly dependent on the diameter of the vessel, the aorta itself and its largest branches are responsible for most arterial compliance seen by blood ejected from the left ventricle. Classically $[11,13]$ in typical human patients the stroke volume in $\mathrm{ml}$ is about 1.5 times pulse pressure in $\mathrm{mmHg}$. That is, in a normal adult 
human the effective aortic compliance is about $1.5 \mathrm{ml} / \mathrm{mmHg}$. However, in patients with significant abnormalities in arterial compliance, such as atherosclerosis and hypertension, the ratio may be substantially different [10]. The present paper shows theoretically that (1) aortic compliance can be determined from aortic pulse wave velocity and aortic volume, both of which can be measured noninvasively and (2) stroke volume can be determined from systolic and diastolic blood pressure and compliance, even in the presence of pulse reflections and continuous runoff of blood from the aorta, also using completely noninvasive measurements.

\section{Estimation of aortic wall compliance}

Figure 1 shows an idealized elastic tube of circular cross section and its pressure-volume curve. The compliance of the tube for small incremental additions of volume is

$$
\mathrm{C}=\frac{2 \pi \mathrm{Lr}^{3}}{\mathrm{Eh}},
$$

where $\mathrm{E}$ is the incremental elastic modulus of the vessel wall, $\mathrm{h}$ is the wall thickness, and $\mathrm{r}$ is the vessel radius [14]. Pulse wave velocity, $\mathrm{v}$, for small volume pulses along an elastic tube containing fluid of mass density, $\rho$, is governed by the Moens-Korteweg equation,

$$
\mathrm{v}=\sqrt{\frac{E \mathrm{~h}}{2 \rho \mathrm{r}}} .
$$

Solving (2a) for E, we have

$$
\mathrm{E}=\frac{2 \rho \mathrm{rv}^{2}}{\mathrm{~h}}
$$

and substituting into Equation (1)

$$
\mathrm{C}=\frac{2 \pi \mathrm{Lr}^{3}}{2 \rho \mathrm{rv}^{2}}=\frac{\pi \mathrm{Lr}^{2}}{\rho \mathrm{v}^{2}}=\frac{\mathrm{V}}{\rho \mathrm{v}^{2}}
$$

in units of $\frac{\mathrm{cm}^{3}}{\frac{\mathrm{g}}{\mathrm{cm}} \times \frac{\mathrm{cm}^{2}}{\mathrm{sec}^{2}}}=\frac{\mathrm{cm}^{3}}{\frac{\mathrm{dmes}}{\mathrm{cm} \mathrm{m}^{2}}}$, where $\mathrm{V}$ is the instantaneous volume of fluid in the tube.

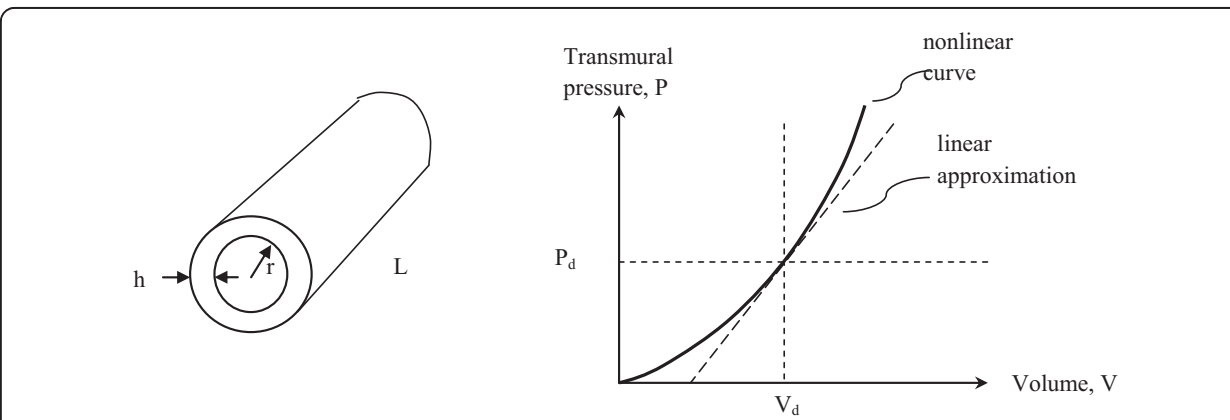

Figure 1 Ideal elastic tube of length, L, wall thickness, h, and inner radius, $r$, and its characteristic volume versus pressure function. The function depends on the elastic properties of the wall material and the difference in pressure across the wall. $V_{d}$ and $P_{d}$ represent reference level, diastolic volume and pressure. 
In clinical units of $\mathrm{ml} / \mathrm{mmHg}$

$$
\mathrm{C}=1333 \frac{\mathrm{V}}{\rho \mathrm{v}^{2}} \quad \frac{\mathrm{cm}^{3}}{\mathrm{mmHg}} .
$$

Equations (3) state that compliance is simply related to the volume of the vessel, the blood density, and the square of the pulse wave velocity. This relationship is identical to the Bramwell-Hill equation [15], first published in 1922, given the definition of compliance as $\Delta \mathrm{V} / \Delta \mathrm{P}$. Importantly in the present context, aortic volume can be estimated noninvasively using external anatomic landmarks to establish the effective length of the aorta and using ultrasound to measure the mid-level cross sectional area of the aortic lumen $[8,16]$. Hence, in principle, aortic compliance can be estimated non-invasively.

\section{From compliance to stroke volume}

Using the relationship, $\mathrm{C}=\Delta \mathrm{V} / \Delta \mathrm{P}$, for the whole aorta, the volume change can be determined from the compliance and the pressure change, under steady state conditions in which the pressure and volume changes are allowed to stabilize. If this state of affairs were strictly true for the aorta, then given a reasonable estimate of compliance, we would have $\mathrm{SV} \approx \mathrm{C} \cdot \Delta \mathrm{P}$, where $\Delta \mathrm{P}$ is pulse pressure. However, in a real aorta the situation is more complicated for three reasons. First, there is continual runoff of blood from the aorta during and following ejection of blood from the left ventricle, so that the aorta is a leaky compliance. Second, a finite time is required for the pulse wave to travel along the aorta from aortic valve to iliac arteries, hence the pressure may not be the same in all parts of the aorta at the same time, especially during the early part of the pulse wave. Third, there are damped reflections of the pulse wave, so that pressure waveforms in proximal and distal aortic sites differ. Nonetheless, techniques for a more refined estimate of compliancebased stroke volume can be derived as follows.

\section{The small animal method}

One more exact formulation of the idea that $\mathrm{SV} \approx \mathrm{C} \cdot \Delta \mathrm{P}$ takes into account the leakage or runoff of blood from the aorta. In smaller animals by the time just after completion of left ventricular ejection the aortic pulse wave has traveled a distance that is equal to or greater than the length of the aorta. At this time, denoted $t_{e}$, the aortic compliance can be estimated as

$$
\mathrm{C}_{\mathrm{ao}} \approx \frac{\mathrm{SV}-\mathrm{CO} \cdot \mathrm{t}_{\mathrm{e}}}{\mathrm{PP}}
$$

where $\mathrm{SV}$ is stroke volume, $\mathrm{CO}$ is cardiac output, $\mathrm{t}_{\mathrm{e}}$ is the ejection time of the left ventricle, and PP is pulse pressure, which is the pressure step-up in the aorta created by ejection. The term $\mathrm{CO}_{\mathrm{e}}$ is a reasonable estimate of the total amount of blood flowing out of the aorta into the peripheral circulation during the time that ejection is occurring. Since cardiac output equals stroke volume multiplied by heart rate, $\mathrm{HR}$, and $1 / \mathrm{HR}=\mathrm{T}$, the cardiac cycle length, we can write

$$
\mathrm{C}_{\mathrm{ao}} \approx \frac{\mathrm{SV}\left(1-\frac{\mathrm{t}_{\mathrm{e}}}{\mathrm{T}}\right)}{\mathrm{PP}}
$$

and solve expression (5) for stroke volume, given estimates of total aortic compliance, pulse pressure, ejection time, and cycle time. 
There is a problem, however. In larger animals, such as humans, the pulse travel time from the aortic valve to the iliac arteries may be longer than the ejection time under some circumstances, and there is not equilibration of pressures throughout the whole aorta. This effect is especially true in more compliant aortas, in which the pulse wave velocity is slower. In taller adult humans with compliant aortas there may be a substantial delay between the arrival of the pulse in the aortic root and the arrival of the pulse in the abdominal aorta, as shown in Figure 2. As a result the whole aorta does not experience uniform pressure (quasi-steady-state conditions) at the end of left ventricular ejection. Under these conditions the effective aortic compliance that receives the stroke volume is less than the total aortic compliance by a varying amount, and the small animal method will not work. In addition, as shown in Figure 2, there are damped reflections that also complicate pulse contours in the first third of the pulse waveform, so that pressures throughout the whole length of the aorta are not the same.

\section{The half time method}

To ensure more steady state conditions one can consider the half time, $t_{h}$, defined as the time after the onset of ejection when blood pressure falls to a point halfway between systolic and diastolic pressures. This time is substantially longer than the pulse propagation delay in humans. Further, by this time the oscillations in pulse pressure have been damped out to a large extent, and pressures at all points along the length of the aorta are similar. At time $t_{h}$ the total aortic compliance then comes into play. The halftime can be determined from the pulse contour, as indicated in Figure 2, which can be recorded noninvasively with external pulse pickups [17-19], including those used to measure pulse wave velocity.

At sample time, $t_{h}$, a larger fraction of the stroke volume has already drained from the aorta into the peripheral circulation than was previously estimated at the end of

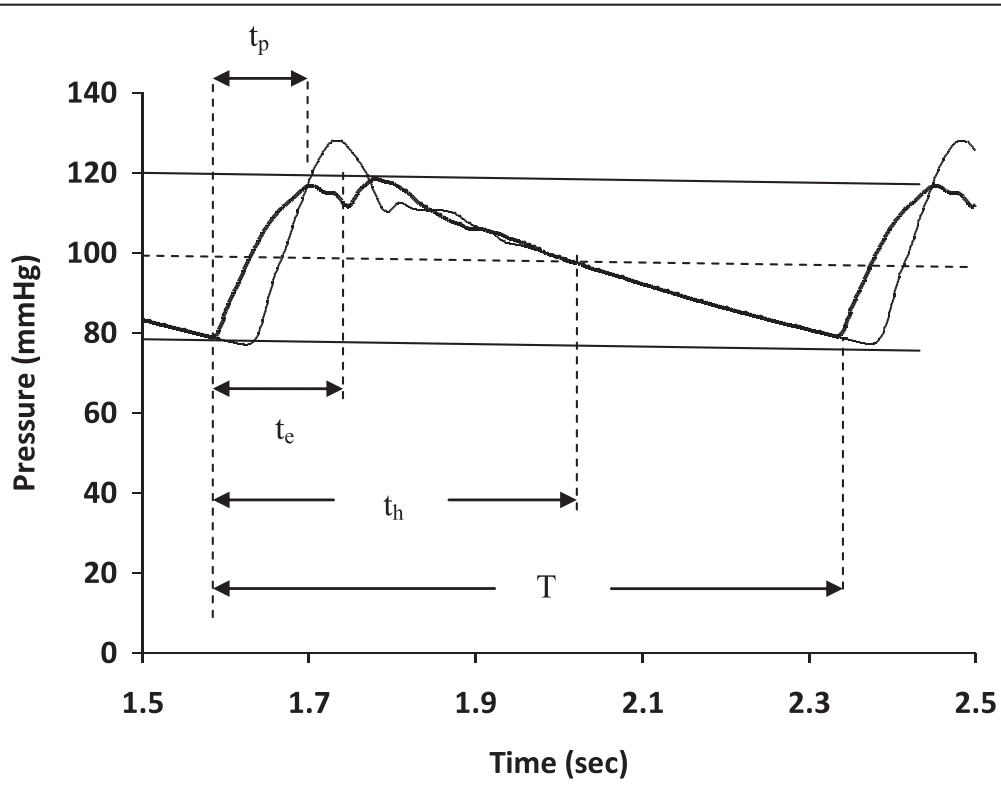

Figure 2 Sketch of pulse waves in proximal and distal aorta with pulse wave delay and resonance effects. Four characteristic times are defined for the first pulse wave to the left. The time from onset to peak is defined as $t_{\mathrm{p}}$. The ejection time is defined as $t_{\mathrm{e}}$. The half time is defined as $t_{\mathrm{h}}$. The cycle length or period of the cardiac cycle is defined as $T$. 
ejection, $t_{\mathrm{e}}$. However, as before, a good initial estimate of the leakage rate is the cardiac output, which provides a slight underestimate of the true leakage rate since average aortic pressure is higher during the first part of the aortic pulse contour. Hence, at time point, $t_{h}$, the total aortic compliance can be written as

$$
\mathrm{C}_{\mathrm{ao}}=\frac{\mathrm{SV}-\lambda \cdot \mathrm{CO} \cdot \mathrm{t}_{\mathrm{h}}}{\frac{\mathrm{PP}}{2}}
$$

where SV is stroke volume, CO is cardiac output, $t_{h}$ is the half time defined in Figure 2, PP is pulse pressure, and $\lambda$ is a dimensionless correction factor slightly greater than one. The factor, $\lambda$, is the ratio of average blood flow rate exiting the aorta (in $\mathrm{mL} / \mathrm{min}$ ) during time interval 0 to $t_{h}$ from the beginning of the pulse, compared to cardiac output. The term $\lambda \cdot \mathrm{CO} \cdot \mathrm{t}_{\mathrm{h}}$ represents the blood flowing out of the aorta into the peripheral circulation during the time interval $t_{h}$. Since cardiac output equals stroke volume divided by the cardiac cycle length, we can write

$$
\mathrm{C}_{\mathrm{ao}}=\frac{2 \cdot \mathrm{SV}\left(1-\lambda \frac{\mathrm{t}_{\mathrm{h}}}{\mathrm{T}}\right)}{\mathrm{PP}}=\frac{2 \cdot \mathrm{CO}\left(\mathrm{T}-\lambda \mathrm{t}_{\mathrm{h}}\right)}{\mathrm{PP}} .
$$

The correction factor, $\lambda$, can be approximated from normal pressure waveforms as about 1.1, or more generally, as shown in Appendix 1, as

$$
\lambda \approx \frac{1+\alpha\left(1-\frac{t_{p}}{t_{h}}\right)}{1-\alpha\left(1+\frac{t_{p}}{T}-2 \frac{t_{h}}{T}\right)},
$$

where $\alpha=\frac{1}{4}\left(\frac{\mathrm{SBP}-\mathrm{DBP}}{(\mathrm{SBP}+\mathrm{DBP}) / 2-\mathrm{CVP}}\right)$, with CVP denoting central venous pressure.

The CVP can be either assumed to be negligible, or if elevated, estimated noninvasively from physical examination of the jugular veins.

Using this approach, one can compute SV and CO from (7) and (8) if total aortic compliance is known.

$$
\mathrm{SV}=\frac{\mathrm{C}_{\mathrm{a} o} \cdot \mathrm{PP}}{2\left(1-\frac{\lambda \mathrm{t}_{\mathrm{h}}}{\mathrm{T}}\right)}
$$

and

$$
\mathrm{CO}=\frac{\mathrm{C}_{\mathrm{ao}} \cdot \mathrm{PP}}{2\left(\mathrm{~T}-\lambda \mathrm{t}_{\mathrm{h}}\right)}
$$

Equations (9) and (10) represent the "halftime method" for obtaining blood flow from pulse pressure and aortic compliance.

\section{Axial tapering and compliance gradients}

An obvious limitation of the forgoing analysis is the assumption of uniform diameter and wall thickness for the entire aorta that is implied in Equation (1). Anatomically, it is well known that the aorta tapers slightly in both its internal and external diameters from the level of the aortic root to the aortic bifurcation. Also wall thickness is greater in the thoracic than in the abdominal portions of the aorta.

To assess the impact of such tapering in an analytical way, consider an elastic tube with a constant wall thickness-to-radius ratio, $\mathrm{h} / \mathrm{r}$, but with radius, $\mathrm{r}$, varying as a function of length. A constant wall thickness to radius ratio of about 0.12 approximates anatomic 
reality and makes the mathematical treatment more straightforward. In this case pulse wave velocity $\mathrm{v}=\sqrt{\mathrm{Eh} /(2 \rho \mathrm{r})}$ becomes independent of the axial position along the aorta, as long as $\mathrm{h} / \mathrm{r}$ and the composition of the aortic wall remain the same. Hence Young's modulus (or the average value of Young's modulus along the aorta) remains $E=2 \rho v^{2}\left(\frac{r}{h}\right)$, as before. In this new scenario, however, let the radius, $r$, of the aorta vary as a function of position, $x$, from its axial midpoint. For a differential segment of length, $\mathrm{dx}$, along the aorta the compliance using Equation (3) is $\mathrm{dC}=\frac{\pi}{\rho v^{2}} \mathrm{r}^{2} \mathrm{dx}$. To describe anatomically realistic tapering of the aorta let $r$ vary as a linear function of $x$, such that $r(x)=r_{0}-\varepsilon x$, where $r_{0}$ is the midpoint of the aorta, with $\mathrm{x}$ extending from $-\mathrm{L} / 2$ to $\mathrm{L} / 2$. Then,

$$
\mathrm{dC}=\frac{\pi}{\rho \mathrm{v}^{2}}\left(\mathrm{r}_{0}^{2}-2 \mathrm{r}_{0} \varepsilon \mathrm{x}+\varepsilon^{2} \mathrm{x}^{2}\right) \mathrm{dx} .
$$

Integrating over length, $\mathrm{L}$, we have

$$
\begin{aligned}
& C=\frac{\pi}{\rho v^{2}} \int_{-L / 2}^{\mathrm{L} / 2}\left(\mathrm{r}_{0}^{2}-2 \mathrm{r}_{0} \varepsilon x+\varepsilon^{2} x^{2}\right) d x \\
& \mathrm{C}=\frac{\pi}{\rho v^{2}}\left(\mathrm{r}_{0}^{2} \mathrm{~L}-2 \mathrm{r}_{0} \varepsilon \frac{1}{2}\left(\frac{\mathrm{L}^{2}}{4}-\frac{\mathrm{L}^{2}}{4}\right)+\varepsilon^{2} \frac{1}{3}\left(\frac{\mathrm{L}^{3}}{8}+\frac{\mathrm{L}^{3}}{8}\right)\right) \\
& \mathrm{C}=\frac{\pi}{\rho \mathrm{v}^{2}}\left(\mathrm{r}_{0}^{2} \mathrm{~L}+\varepsilon^{2} \frac{\mathrm{L}^{3}}{12}\right)=\frac{\pi \mathrm{r}_{0}^{2} \mathrm{~L}}{\rho \mathrm{v}^{2}}\left(1+\frac{1}{12} \varepsilon^{2} \frac{\mathrm{L}^{2}}{\mathrm{r}_{0}^{2}}\right) .
\end{aligned}
$$

Note that if the total taper, $\varepsilon \mathrm{L}$, is less than $\mathrm{r}_{0}$, then for this model, the compliance of the tapered aorta is only slightly greater than that of an un-tapered aorta having the middle value of radius. From the data of Voges et al. [20] we can estimate that $\varepsilon \mathrm{L} / \mathrm{r}_{0}$ is approximately $6 \mathrm{~mm} / 8 \mathrm{~mm}$, giving about a $4 \%$ difference in total compliance with tapering vs. a model of uniform thickness. This is an acceptable error for clinical purposes. If desired, the tapering correction term in parentheses could be taken as a constant for humans, approximately equal to 1.04. Accurate determination of the mid-level aortic cross sectional area, $\pi r_{0}^{2}$, however, remains important. Also, the issue of nonlinear compliance must be addressed, as shown subsequently.

\section{Noninvasive data acquisition}

Pulse wave velocity

At least three different commercial systems are available for measuring aortic pulse wave velocity from external sensors placed over the carotid and femoral arteries [7,21]. These devices detect the carotid and femoral pulses using external pulse pickups $[18,19]$ and employ sophisticated algorithms such as cross correlation $[22,23]$ to determine the time delay between pulses. The time delay is divided into an estimate of effective aortic length to obtain aortic pulse wave velocity. Commercial systems give pulse wave velocities between about 8 and $10 \mathrm{~m} / \mathrm{sec}$ for typical adult patients having some degree of atherosclerosis [7].

\section{Aortic volume}

Conventional ultrasound sector scanning can be used to determine aortic cross sectional area in the high abdominal or lower thoracic aorta near its midpoint [8]. One can use external landmarks to estimate the effective length of the aorta, for example as the distance from supra-sternal notch to either anterior-superior iliac spine. For use in 
Equation (3) the effective length, $\mathrm{L}$, is defined as the length of an un-branched tube having the same total compliance as the natural aorta and its largest (brachiocephalic, carotid, and iliac) branches. The effective length, $\mathrm{L}$, is slightly longer than the anatomic distance from the aortic valve in the chest to the aortic bifurcation in the mid abdomen, including the curvature of the aortic arch. Blood density is essentially constant at $1.03 \mathrm{~g} / \mathrm{ml}$. Combining these values in Equation (3) gives a noninvasive estimate of total aortic compliance.

\section{Pressures and time intervals}

Systolic and diastolic aortic pressures can be determined in the usual way using an external arm cuff or an indwelling arterial catheter. Characteristic time, $\mathrm{t}_{\mathrm{h}}$, and cycle length, $\mathrm{T}$, can be determined from a noninvasive pulse pickup that records the pulse contour.

In this way cardiac output and stroke volume can be estimated quantitatively from a suite of noninvasive measurements, based on the underlying physics of the aorta. These measurements can be combined to provide estimates of stroke volume by the halftime method. A simple spreadsheet on a laptop computer or application on a smart phone can be programmed to do the calculations automatically, given the input data.

\section{Testing the proposed methods in a computer model of the circulation} Test system

The accuracy of the proposed method can be tested and refined using a computational model of the human systemic circulation. In such a model one can compute pulse wave velocity from proximal and distal pulse waveforms and utilize instantaneous aortic cross sectional area to estimate aortic compliance. In turn, one can compute pulse contour parameters and stroke volume using the halftime method, comparing the results vs. "actual" values in the model. This test system can mimic the details of an idealized aorta in a way that makes it straightforward to investigate possible confounding effects such as, varying stiffness, nonlinear compliance, varying myocardial contractility, and varying heart rate, including both normal and shock-like states.

A simple, 12-compartment numerical model of the aorta and systemic circulation is shown in Figure 3. $R_{i}$ and $R_{o}$ represent the resistances associated with the input and output valves of the left ventricular pump, labeled $C_{p}$. Compliant compartments $C_{a 0}$

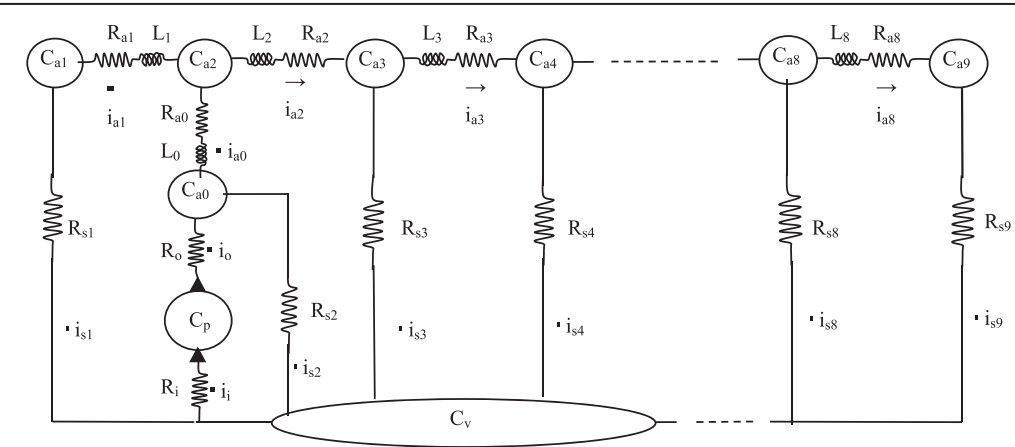

Figure 3 Mock circulatory system for the numerical model. Compliances are denoted C. Inertances are denoted L. Resistances are denoted R. Flows are denoted i. Solid triangles indicate one-way heart valves. To simulate left ventricular contraction an external, squeezing pressure, $P_{\text {ext }}(t)$, having a half sinusoidal waveform is applied to the pump compliance, $C_{p}$, namely $P_{\text {ext }}(t)=P_{\max } \cdot \max (0, \sin (\omega t))$, where $P_{\max }$ is the peak applied pressure. To create a range of stroke volumes in the model $P_{\max }$ is varied from 25 to $175 \mathrm{mmHg}$. Full details of model construction and operation are provided in Appendix 2. 
through $C_{a 9}$ represent segments of the aorta and its largest branches. Segment $C_{a 0}$ represents the aortic root, and segment $C_{a 2}$ represents the aortic arch. Segment $C_{a 1}$ represents the brachiocephalic arteries, and segment $C_{a 9}$ represents the two iliac arteries. The remaining compliant segments represent the descending thoracic aorta and abdominal aorta.

Small resistances $R_{a 0}, R_{a 1}, R_{a 2}$, through $R_{a 9}$ connect the 10 discrete aortic segments. Resistances $R_{a 1}$ and $R_{a 9}$ are larger than the other in-line aortic resistance values and represent the damping effects of the more narrow brachiocephalic and iliac arteries and their branches. The in-line aortic resistances were adjusted to give a physically realistic degree of damping to the aortic pulse waveform. The parallel resistances $R_{s 1}$ through $R_{s 9}$ represent systemic vascular resistance. The values of $R_{s 1}, R_{s 2}$, etc. are over 1000 times larger than the in-line aortic resistances. Included also are inertances, $\mathrm{L}$, representing the inertia of each segment of the aortic blood column. These are computed as the product of fluid density and segment length, divided by segment cross sectional area [24]. The inertances of the venae cavae are assumed to be zero. Their effects are much smaller than those of aortic inertances owing to the much slower blood velocity in the great veins as well as the larger cross sectional areas of the blood columns in the great veins and right atrium. Vascular compliances are denoted by $\mathrm{C}$. The aortic compliances $\mathrm{C}_{\mathrm{a} 0}$ through $\mathrm{C}_{\mathrm{a} 9}$ may take on a range of values from normal to stiff, representing severe atherosclerosis. Numerical values for these and other model parameters are derived in detail in Appendix 2, and are based

Table 1 Model parameters for a normal adult human

\begin{tabular}{|c|c|c|c|}
\hline Parameter & Value & Units & Description \\
\hline \multicolumn{4}{|l|}{ Resistances } \\
\hline Rs1 - Rs9 & 10.3 & $\mathrm{mmHg} /(\mathrm{ml} / \mathrm{sec})$ & Local systemic resistance \\
\hline $\mathrm{Ri}$ & 0.01 & $\mathrm{mmHg} /(\mathrm{ml} / \mathrm{sec})$ & Pump input resistance \\
\hline Ro & 0.01 & $\mathrm{mmHg} /(\mathrm{ml} / \mathrm{sec})$ & Pump output resistance \\
\hline $\mathrm{Ra0}, \mathrm{Ra} 2-\mathrm{Ra} 8$ & 0.005 & $\mathrm{mmHg} /(\mathrm{ml} / \mathrm{sec})$ & Aortic segment resistance \\
\hline Ra1, Ra9 & 0.1 & $\mathrm{mmHg} /(\mathrm{ml} / \mathrm{sec})$ & Carotid and femoral resistance \\
\hline \multicolumn{4}{|l|}{ Compliances } \\
\hline $\mathrm{CaO}-\mathrm{Ca} 9$ & 0.13 & $\mathrm{ml} / \mathrm{mmHg}$ & Compliance of an aortic segment \\
\hline Cv & 10 & $\mathrm{ml} / \mathrm{mmHg}$ & Compliance of lumped venous reservoir \\
\hline$C p$ & 12 & $\mathrm{ml} / \mathrm{mmHg}$ & Pump compliance in diastole \\
\hline \multicolumn{4}{|l|}{ Dimensions } \\
\hline SegLength & 5 & $\mathrm{~cm}$ & Aortic segment length \\
\hline SegRadius & 1.5 & $\mathrm{~cm}$ & Initial aortic segment inner radius \\
\hline VenousVol & 2000 & $\mathrm{ml}$ & Initial volume of lumped veins \\
\hline PumpVol & 200 & $\mathrm{ml}$ & Initial pump volume \\
\hline \multicolumn{4}{|l|}{ Knobs } \\
\hline frequency & 1.3333 & $\mathrm{~Hz}$ & Cardiac frequency (heart rate) \\
\hline Pmax & 120 & $\mathrm{mmHg}$ & Maximal external pump pressure \\
\hline $\mathrm{dt}$ & 0.00001 & sec & Time step for numerical integration \\
\hline startprint & 1.5 & $\mathrm{sec}$ & Time at which output data start being plotted \\
\hline stopprint & 3 & sec & Time at which output data stop being plotted \\
\hline skipnumber & 99 & & Number of calculated points skipped between plotted point \\
\hline Pinit & 10 & $\mathrm{mmHg}$ & Initial equilibrium pressure of arrested circulation \\
\hline
\end{tabular}


upon textbook physiology and anatomy. Standard values for the normal circulation are shown in Table 1.

\section{Nonlinear compliance}

One obvious difference between the simple test system in Figure 3 and a living subject is that over a wide range of possible physiologic pressures in a given individual dynamic arterial compliance is not constant $[14,25]$. Instead the compliance is "nonlinear" because the volume vs. pressure function for arteries is curved over the complete pathophysiologic range. Its slope, the dynamic compliance, varies as a function of pressure. However, a simple modification of the model in Figure 3 can be introduced to mimic the nonlinear characteristics of biological tissues.

\section{Mathematical model}

The classical nonlinear mechanical properties of tissues such as artery walls have been well characterized by Y. C. Fung [26]. For a tube with walls composed of a classical Fungian biomaterial, the pressure domain analog to the stress-strain relationship would be

$$
\mathrm{P}=\mathrm{P}_{\mathrm{ref}}\left(\mathrm{e}^{\mathrm{b}\left(\mathrm{v}-\mathrm{v}_{0}\right) / \mathrm{v}_{0}}-1\right) \text {. }
$$

The reference pressure $\mathrm{P}_{\text {ref }}$ refers to the pressure at which a fixed experimental value for dynamic compliance is determined, as will be seen. $V_{0}$ represents the zero pressure volume. The use of volume rather than circumferential wall stretch in the exponent is simply accounted for by adjustment of the constant, b. To obtain an expression for nonlinear dynamic compliance, we can recast Equation (13) as,

$$
\ln \left(\frac{\mathrm{P}}{\mathrm{P}_{\text {ref }}}+1\right)=\frac{\mathrm{b}\left(\mathrm{V}-\mathrm{V}_{0}\right)}{\mathrm{V}_{0}} \text {, or } \mathrm{V}=\mathrm{V}_{0}+\frac{\mathrm{V}_{0}}{\mathrm{~b}} \times \ln \left(\frac{\mathrm{P}}{\mathrm{P}_{\text {ref }}}+1\right) \text {. }
$$

The dynamic compliance is therefore

$$
\frac{\mathrm{dV}}{\mathrm{dP}}=\frac{\mathrm{V}_{0}}{\mathrm{~b}} \cdot \frac{1}{\frac{\mathrm{P}}{\mathrm{P}_{\mathrm{ref}}}+1} \cdot \frac{1}{\mathrm{P}_{\mathrm{ref}}}=\frac{\mathrm{V}_{0}}{\mathrm{~b}} \cdot \frac{1}{\mathrm{P}+\mathrm{P}_{\mathrm{ref}}}
$$

When $\mathrm{P}=\mathrm{P}_{\text {ref }}$ we have $\frac{\mathrm{dV}}{\mathrm{dP}}=\frac{\mathrm{V}_{0}}{2 \mathrm{~b}} \cdot \frac{1}{\mathrm{P}_{\text {ref }}}=\mathrm{C}_{\text {ref }}$, which is the dynamic compliance at the reference pressure, for example, diastolic arterial pressure in the context of the present problem. In turn,

$$
\begin{aligned}
& \frac{\mathrm{V}_{0}}{\mathrm{~b}}=2 \mathrm{C}_{\text {ref }} \mathrm{P}_{\text {ref }} . \text { So that } \\
& \frac{\mathrm{dV}}{\mathrm{dP}}=2 \mathrm{C}_{\text {ref }} \cdot \frac{\mathrm{P}_{\text {ref }}}{\mathrm{P}+\mathrm{P}_{\text {ref }}}
\end{aligned}
$$

as a function of pressure only. Here the reference pressure $P_{\text {ref }}$ is analogous to the reference tension $T^{*}$ in Fung's original model. One can take $\mathrm{P}_{\text {ref }}$ as the reference pressure at which the aortic compliance is normally determined, such as normal diastolic arterial pressure $\left(80 \mathrm{mmHg}\right.$ ) and convert linear compliances, $\mathrm{C}_{\mathrm{ref}}$, into nonlinear ones, using Equation (16). In this way the numerical model of the mock circulation is easily modified for nonlinear dynamic compliance of the aorta by using expression (16) in place of $\mathrm{C}_{\mathrm{ref}}$. As instantaneous distending pressure, $\mathrm{P}$, becomes greater than $\mathrm{P}_{\text {ref }}$, the dynamic compliance becomes less than the nominal value, $\mathrm{C}_{\text {ref. }}$. As instantaneous distending pressure, $\mathrm{P}$, becomes less then 
$\mathrm{P}_{\text {ref, }}$, the dynamic compliance becomes greater than the nominal value, $\mathrm{C}_{\mathrm{ref}}$, mimicking the changes in slope of the nonlinear pressure-volume curve in Figure 1.

\section{Numerical methods}

To make the model circulation go, a positive external, squeezing pressure having a half sinusoidal waveform is applied to the pump compartment. Instantaneous blood flows, volume changes, and pressure changes in all compartments of the model are computed during each discrete time step $\Delta \mathrm{t}=0.00001 \mathrm{sec}$. These changes are numerically integrated, using the simple Euler method, to give time domain records of instantaneous volumes and pressures in all model compartments, as explained in detail in Appendix 2. The simulations begin with a cold start at the initial vascular volumes and a "mean circulatory pressure" of the arrested circulation of $10 \mathrm{mmHg}$ in all compartments. The left ventricular pressure function is turned on, and at successive time steps, $\Delta t$, the following variables are computed to create a marching solution for flows, volumes, and pressures:

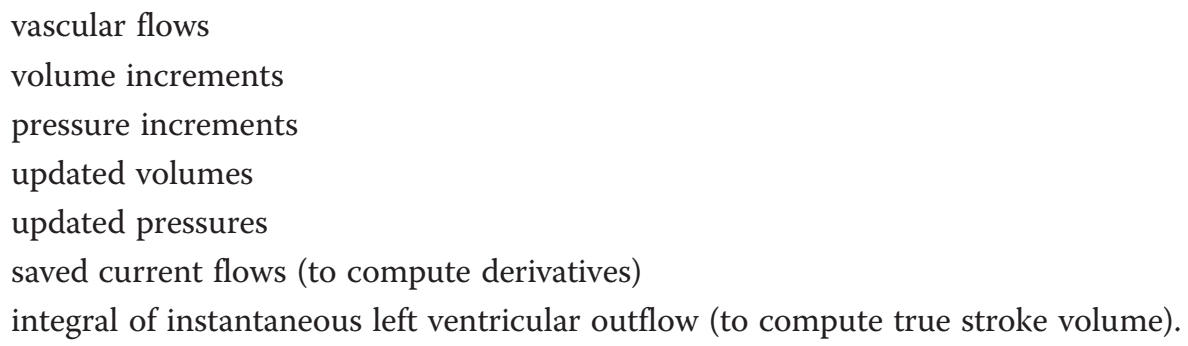

This process is iterated over 300,000 time steps to track evolution of the system over a $3 \mathrm{sec}$ test period. The model was solved using Microsoft Visual Basic Macros within a Microsoft Excel spreadsheet, running on a laptop computer, to perform numerical integration. Data are saved for plotting after each 100 time steps (1 kHz sample rate). Steady state pressures are reached after the second heartbeat in this simple system. In addition to pressure and volume waveforms, the aortic radii at each segmental level are computed from the square root of volume/( $\pi$.length) of each segment as a surrogate for aortic dimensions visualized by ultrasound. Stroke volume during the interval of data recording, corresponding to a whole number, $n$, of heartbeats, is computed as

$$
\mathrm{SV}=\frac{1}{\mathrm{n}} \int \mathrm{i}_{\mathrm{o}} \mathrm{dt}
$$

\section{Extraction of parameters from simulated pulse contours}

To determine pulse wave velocity for the model circulation in Figure 3 the time interval between upstrokes of the aortic pulse waveforms in segments 2 and 8 was measured directly and divided into the center-to-center distance between the segments. The time difference was measured at a pressure corresponding to diastolic pressure plus 2 percent of the pulse pressure. These points marked the very beginning of the pulse upstroke and corresponded to aortic cross sections at the diastolic level. They are relatively insensitive to reflected wave augmentation in the arterial pressure waveform.

The representative cross sectional area of the aorta, as would be determined by ultrasound, was determined from the average of the diastolic radii of the mid aortic segments (which were quite similar). Blood density was taken as $1.03 \mathrm{~g} / \mathrm{cm}^{3}$. Total aortic compliance 
was calculated using Equation (3b), with aortic volume computed as the product of midlevel cross section and the total length of the ten arterial segments. (That is, for the purposes of this simulation the effective length of the aorta was taken as the actual length.) The time interval $t_{h}$, representing the half time was computed from the contour of the function of aortic radius vs. time, working backwards from a time point just prior to the next diastolic point to avoid possible large oscillations after the peak of the pulse. Then stroke volume was computed using the half time formula of Equation (9). Integrated flow across the aortic valve (Equation (17)) was used as the reference, or actual stroke volume.

\section{Results}

\section{Estimation of aortic compliance}

In Figure 4(a) the estimated compliance values based on pulse wave velocity are plotted as a function of actual model compliance over a range of $1 / 3$ to 1.5 times normal for a typical adult human. (Here 1/3 normal compliance corresponds to severe atherosclerosis, $1 / 2$ normal compliance corresponds to moderate atherosclerosis, etc.) In this first test the model compliance was constant as a function of time and pressure, that is, the volume increased linearly with pressure (a linear compliance model). In this case the true value of model compliance served as a stable reference. The aortic model had constant diameter and material properties along its length. In Figure 4(a) the solid data points represent non-invasively estimated compliance, computed using Equation (3b). The dashed line represents the actual total arterial compliance of the model.

Pulse wave velocities calculated from pulse transit times for $1 / 3,1 / 2,1$, and $3 / 2$ normal aortic compliance were 1034, 857, 667, and $577 \mathrm{~cm} / \mathrm{sec}$ respectively. Commercial systems give pulse wave velocities between about 8 and $10 \mathrm{~m} / \mathrm{sec}$ for typical adult patients [7], who would be expected to have atherosclerosis and relatively stiff, less compliant, aortas. These are quite similar to those in the mock circulation for $1 / 3$ and $1 / 2$ normal aortic compliance.

Figure (4b) shows the ratio of stroke volume computed from pulse wave velocity and aortic cross section compared to actual stroke volume in the model over a range of aortic compliances from $1 / 3^{\text {rd }}$ to 1.5 times normal. The halftime method of Equation (9) was used to estimate stroke volume. The agreement for the simple linear compliance model is satisfactory.

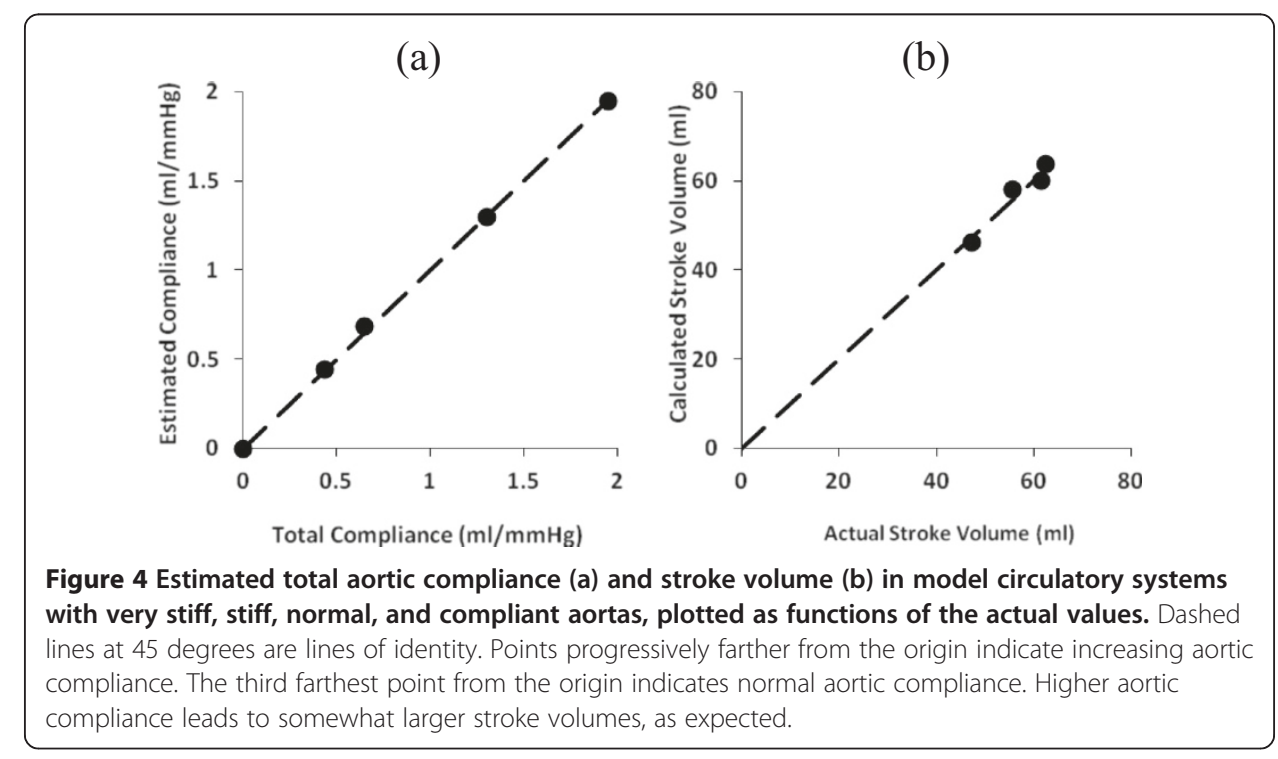




\section{Dealing with nonlinear compliance}

Figure 5(a) shows results from a modified aortic model of constant diameter and nonlinear dynamic compliance, computed at each time step of the numerical integration using Equation (16). As before, non-invasively estimated compliance was computed using equation (3b) from pulse wave velocity and model aortic volume without any correction for nonlinearity. Stroke volume was computed using Equation (9) over a range of peak left ventricular pressures from 25 to $175 \mathrm{mmHg}$, which produced actual stroke volumes ranging from roughly one quarter to twice normal. Figure 5(a) shows the estimated stroke volume computed from pulse wave velocity and aortic cross section compared to actual stroke volume in a typical model with normal aortic compliance. The estimated values slightly overestimate true stroke volume, especially at higher pulse pressures. Here the pulse wave velocity method is giving diastolic compliance, but the average compliance of the aorta over the time that blood is draining into the periphery is less, because of the nonlinear effect. In turn, the observed pulse pressure is greater than expected for the diastolic compliance level. Stroke volume estimates based on the product of observed pulse pressure and observed diastolic compliance are greater with nonlinear compliance, especially at higher pulse pressures.

The overestimate can be corrected, in large part, as shown in Figure 5(b), using the following nonlinear compliance correction for pressures in units of $\mathrm{mmHg}$,

$$
\frac{\mathrm{SV}^{\prime}}{\mathrm{SV}}=\frac{2(\mathrm{DBP}+80)}{\mathrm{PP}} \ln \left(1+\frac{\mathrm{PP}}{2(\mathrm{DBP}+80)}\right)
$$

which is derived in detail in Appendix 3. In Equation (18a) SV' indicates the computed stroke volume estimate in the presence of nonlinear compliance characteristics typical of a classical Fungian biomaterial. SV indicates the stroke volume estimate of Equation (9) that is computed assuming constant compliance, PP is the pulse pressure, and DBP is the diastolic blood pressure, both in units of $\mathrm{mmHg}$. The function $\ln (\mathrm{x})$ is the natural logarithm of $\mathrm{x}$. In the limiting case for small values of pulse pressure, PP, one can use the series approximation for $\varepsilon<<1$

(a)

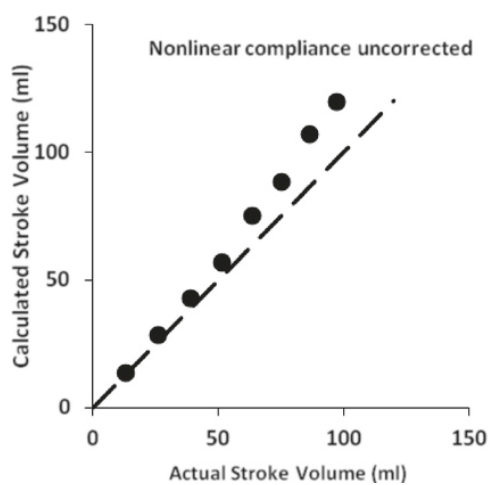

(b)

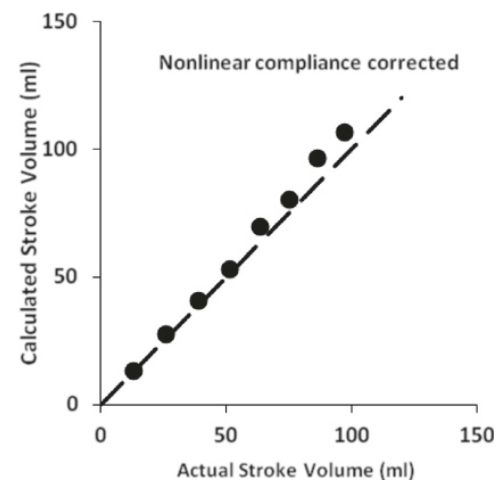

Figure 5 Estimated stroke volumes in model circulatory systems with nonlinear compliance, plotted as functions of the actual values used as model inputs over a range of peak left ventricular pressure values and consequent aortic pressures. (a) uncorrected data computed assuming constant aortic compliance (b) corrected data for nonlinear compliance in a classical Fungian biomaterial. Heart rate was $80 / \mathrm{min}$. Dashed lines at 45 degrees are lines of identity. 


$$
\begin{aligned}
& \ln (1+\varepsilon) \approx \varepsilon-\frac{1}{2} \varepsilon^{2}=\varepsilon\left(1-\frac{1}{2} \varepsilon\right), \text { so that } \\
& \frac{\mathrm{SV}^{\prime}}{\mathrm{SV}} \approx 1-\frac{1}{4} \frac{\mathrm{PP}}{\mathrm{DBP}+80} .
\end{aligned}
$$

This form of expression (18a) shows that for small pulse pressures the correction factor approaches 1.00 . For increasingly larger pulse pressures the correction factor becomes progressively less than 1.00 .

When the correction ratio (18a) is applied to the data in Figure 5(a) the results in Figure 5(b) are obtained. The systematic overestimation of stroke volume at larger pulse pressure is largely eliminated. The correlation coefficient $\left(r^{2}\right)$ for estimated vs. actual stroke volume in Figure 5(b) is 0.998.

\section{Varying heart rate}

Figure 6 shows noninvasively estimated stroke volume vs. actual stroke volume for a fast heart rate (120/min) as might occur in patients with heart failure or shock-like states. The correlation coefficient $\left(\mathrm{r}^{2}\right)$ for estimated vs. actual stroke volume after nonlinear compliance correction was 0.983 .

\section{Discussion}

A global emphasis on cost effectiveness in medicine has made it timely to revisit the issue of noninvasive measurement of cardiac output and stroke volume, which remains an open problem in biomedical engineering. Classical standard methods, inducing the Fick and indicator dilution techniques, require centrally placed right heart catheters to sample mixed venous blood or to gain access to the combined circulatory flow in the pulmonary artery. Pulse contour methods frequently require at least one invasively obtained calibration value, which should be repeated if mean aortic pressure changes, owing to the nonlinear compliance of the aorta. Bio-impedance methods [6,27] are fully noninvasive, but somewhat difficult to calibrate, although novel front-to-back electrode placements can help to

(a)

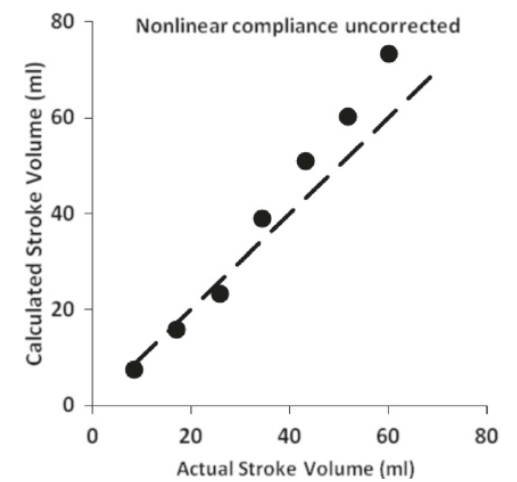

(b)

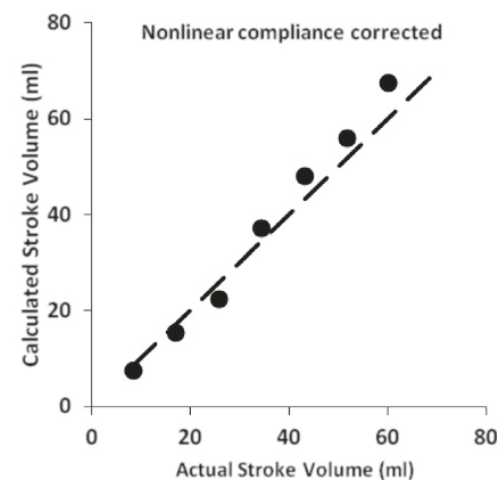

Figure 6 Estimated stroke volumes in model circulatory systems with nonlinear compliance, plotted as functions of the actual values used as model inputs over a range of peak left ventricular pressure values and consequent aortic pressures. (a) uncorrected data computed assuming constant aortic compliance (b) corrected data for nonlinear compliance in a classical Fungian biomaterial. Heart rate was 120/min. Dashed lines at 45 degrees are lines of identity. 
give a fully noninvasive estimate of cardiac ejection fraction, if not absolute stroke volume [28]. The present paper proposes a new strategy, based on an old equation [15] that allows for fully noninvasive estimates of the absolute value of stroke volume, and in turn, cardiac output. The results show that it is at least theoretically possible to obtain accurate estimates of stroke volume in human adults over a wide range of aortic stiffnesses, heart rates, and ejection fractions. Moreover, the calculations can account gracefully for nonlinear aortic compliance. Unlike other non-invasive techniques for estimating cardiac output, which have been well reviewed [6,29], the present method does not involve proprietary algorithms. The validity and assumptions of the approach are fully open to evaluation. Modifications and refinements can be made easily in response to future laboratory and clinical experience. Of course, pulse wave velocity based estimates of stroke volume would be precluded in patients with severe cardiac arrhythmias and in patients with intra-aortic balloon pumps. In such patients a pulmonary artery catheter may be justified.

\section{Propagation of errors from multiple measurements}

A potential weakness of the proposed technique is the precision with which pulse transit time and pulse wave velocity can be measured, since the computed compliance depends on the square of the pulse wave velocity. There is also potential error in the cross sectional area of the aorta near its midpoint, as measured by ultrasound, as well as in externally measured systolic and diastolic blood pressures and in the cardiac cycle length and halftime values.

To analyze error compounding in the proposed technique one can estimate the statistical propagation of errors in the formula for cardiac output

$$
\mathrm{CO}=\frac{\mathrm{C}_{\mathrm{est}} \cdot \mathrm{PP}}{2\left(\mathrm{~T}-\lambda \mathrm{t}_{\mathrm{h}}\right)}=\frac{\mathrm{A}_{\mathrm{mid}} \mathrm{L}}{2 \rho \mathrm{v}^{2}} \frac{\mathrm{PP}}{\mathrm{T}-\lambda \mathrm{t}_{\mathrm{h}}} .
$$

The principal uncertainties are in the aortic cross section, $A_{\text {mid }}$, the effective length estimate, L, the pulse pressure, PP, the pulse wave velocity, v, and the lumped timing factor $\left(\mathrm{T}-\lambda \mathrm{t}_{\mathrm{h}}\right)$. One can explore random variation in calculated cardiac output as a function of the random variation in these five quantities, especially the squared pulse wave velocity term. This analysis is analogous to the following statistical problem. Consider uncorrelated random variables $\mathrm{X}, \mathrm{Y}, \mathrm{Z}, \mathrm{U}, \mathrm{V}$, and $\mathrm{S}$ such that

$$
\mathrm{S}=\frac{\mathrm{XY}}{\mathrm{Z}^{2}} \cdot \frac{\mathrm{U}}{\mathrm{V}}
$$

Let $\overline{\mathrm{X}}$ denote the mean of random variable, $\mathrm{X}, \sigma(\mathrm{X})$ denote the standard deviation of $\mathrm{X}$, and $\sigma^{2}(\mathrm{X})$ denote the variance of $\mathrm{X}$, and similarly for the other random variables. Taking natural logarithms,

$$
\ln (\mathrm{S})=\ln (\mathrm{X})+\ln (\mathrm{Y})-2 \ln (\mathrm{Z})+\ln (\mathrm{U})-\ln (\mathrm{V})
$$

For uncorrelated variables that are added or subtracted the variances add, such that

$$
\sigma^{2}(\ln (\mathrm{S}))=\sigma^{2}(\ln (\mathrm{X}))+\sigma^{2}(\ln (\mathrm{Y}))+4 \sigma^{2}(\ln (\mathrm{Z}))+\sigma^{2}(\ln (\mathrm{U}))+\sigma^{2}(\ln (\mathrm{V})) .
$$

We can use the relationship for the variance of the natural logarithm of a random variable (Appendix 4) 


$$
\begin{aligned}
& \sigma^{2}(\ln (\mathrm{X})) \approx \frac{\sigma^{2}(\mathrm{X})}{\overline{\mathrm{X}}^{2}}, \text { to give } \\
& \frac{\sigma^{2}(\mathrm{~S})}{\overline{\mathrm{S}}^{2}} \approx \frac{\sigma^{2}(\mathrm{X})}{\overline{\mathrm{X}}^{2}}+\frac{\sigma^{2}(\mathrm{Y})}{\overline{\mathrm{Y}}^{2}}+4 \frac{\sigma^{2}(\mathrm{Z})}{\overline{\mathrm{Z}}^{2}}+\frac{\sigma^{2}(\mathrm{U})}{\overline{\mathrm{U}}^{2}}+\frac{\sigma^{2}(\mathrm{~V})}{\overline{\mathrm{V}}^{2}} .
\end{aligned}
$$

A good index of variability in a positive random variable is the coefficient of variation, defined as the standard deviation divided by the mean. For the composite random variable, $\mathrm{S}$,

$$
\frac{\sigma(\mathrm{S})}{\overline{\mathrm{S}}}=\sqrt{\frac{\sigma^{2}(\mathrm{X})}{\overline{\mathrm{X}}^{2}}+\frac{\sigma^{2}(\mathrm{Y})}{\overline{\mathrm{Y}}^{2}}+4 \frac{\sigma^{2}(\mathrm{Z})}{\overline{\mathrm{Z}}^{2}}+\frac{\sigma^{2}(\mathrm{U})}{\overline{\mathrm{U}}^{2}}+\frac{\sigma^{2}(\mathrm{~V})}{\overline{\mathrm{V}}^{2}}} .
$$

This result is similar to the general rule for the propagation of errors in chemical measurements [30]. For example if X, Y, Z, U, and V each have a coefficient of variation, $\varepsilon$, then

$$
\frac{\sigma(\mathrm{S})}{\overline{\mathrm{S}}} \approx \sqrt{8 \varepsilon^{2}} \approx 2.8 \varepsilon .
$$

And if $\varepsilon=0.05$, then $\frac{\sigma(S)}{\bar{S}} \approx 0.14$. If there are $5 \%$ errors each in the aortic cross section, pulse pressure, aortic length estimate, lumped timing factor, and pulse wave velocity, then the expected variation in computed cardiac output would be 14 percent. The $95 \%$ confidence limits, roughly two standard deviations, would be 28 percent of the mean value. This estimate is within the clinically acceptable limit of 30 percent variation, proposed by Critchley and Chritchley [31].

The potential lack of precision in noninvasively estimated cardiac output must be compared with the lack of precision in established "gold standard" techniques, which is also non-trivial [31]. The Fick method, for example is an aggregate of independent measurements of oxygen uptake and arteriovenous oxygen difference. The indicator dilution method requires independent measurements of the amount of dye injected and the area under the dilution curve compared to baseline. The estimate using Equation (25) is similar to that of other alternative methods of measuring cardiac output as reviewed by Geerts [6], in which coefficients of variation ranged from 5 to 15 percent. Hence, then proposed noninvasive approach would appear to have potential precision similar to that of existing methods with fewer drawbacks and complications.

More precise measurements of the component variables, would lead to correspondingly better estimates of stroke volume. An important opportunity for increasing precision is the ability to sample and average data for 10 to perhaps 100 heartbeats using an automated data collection system. Random variations can be reduced substantially by such averaging. It remains as a challenge to experimentalists to create practical systems with sufficient precision for practical, clinical implementation.

In discussing the overall validity of the proposed method, however, it is important to distinguish between errors in accuracy introduced by constant biases and true random biological variation. Constant systematic biases may be introduced into the calculations, but are less troublesome than unpredictable random variations. For example, in determining the effective aortic length, L, based on superficial landmarks, it may well be that the actual aortic length is, on average, say, 10 percent more than the landmark based measurement, with individual patients varying somewhat about this value. In determining the precision of the method the constant average bias is not important. Clinicians 
can easily adapt to a constant 10 percent overestimate of stroke volume. Changes over time in the management of an individual patient remain easy to recognize and interpret. Further, with experience such constant biases can be reduced to acceptable levels.

There are alternative solutions to the problem at hand. The lack of evidence for the cost effectiveness of invasive hemodynamic monitoring using a pulmonary artery catheter [32] has prompted commercialization of systems to track changes in stroke volume by pulse contour analysis. These systems have been well reviewed [6,13,29,33]. The PiCCO System (Pulsion Medical Systems, Munich, Germany) derives stroke volume estimates from the diastolic to systolic integral of the pulse contour, which is calibrated by invasive thermal dilution measurements, using a dedicated catheter typically placed in the femoral artery. The calibration must be repeated every time there is a significant hemodynamic change. The LiDCO plus system (LiDCO, Cambridge, UK) uses a proprietary pulse pressure algorithm (PulseCOTM) based on the change in power in the arterial tree and repeated lithium dilution for calibration. These systems allow continuous monitoring of changes in hemodynamics but still require placement of invasive catheters for calibration. The Flotrac system (Edwards Lifescience, Irvine, CA, USA) incorporates a specific transducer that may allow calibration using a non-central arterial line for accurate waveform acquisition with calibration based on nomograms using the age, weight, and sex of the patient to estimate compliance. The Flowtrac algorithm uses a multivariate scaling parameter reflecting the effects of vascular tone on pulse pressure that is computed from a polynomial equation. None of these systems is truly noninvasive.

A completely noninvasive approach has been described classically by Huntsman and coworkers [16], who used ultrasound to measure the volume of blood moving through the ascending aorta during systole. The blood velocity was calculated from Doppler measurements and the cross sectional area was measured in $\mathrm{A}$ mode or $\mathrm{M}$ mode. Stroke volume was calculated as V x ET x CSA, where V = the spatial average blood velocity in the aorta during systole, ET = ejection time and CSA = the cross-sectional area of the lumen. Of course the roughly 7 percent of stroke volume flowing into the coronary arteries would be missed by this method. The approach appears to be relatively dependent on the skill of the operator, requiring 10-15 minutes for the initial diameter assessment [16] by unhurried examination of the anatomy and repeated diameter determinations. In addition, the first velocity measurement may take as long as 5 minutes. Nonetheless, this classic paper shows the clinical feasibility of fully noninvasive measurements of stroke volume and cardiac output.

\section{Conclusions}

The present analytical and numerical modeling exercise suggests that a completely noninvasive pulse wave velocity based method for measuring stroke volume can in principle be accurate, despite pulse wave reflections within the aorta and nonlinear vascular compliance. That is, it can give the true value in the absence of noise. Follow-on clinical studies are needed to determine if the real-world precision of this approach is sufficient for monitoring the circulatory status of critically ill patients and if the method is practical and feasible in real-world clinical settings. 


\section{Appendix 1: estimation of $\lambda$ - flow during the halftime interval vs. cardiac output}

For mathematical convenience one can model the pulse wave as a piecewise linear function rising from the diastolic point to the systolic point, then falling to the halftime point, and then falling to the next diastolic point, as shown in Figure 7.

\section{Define}

SBP as systolic arterial pressure

DBP as diastolic arterial pressure

$\mathrm{PP}$ as pulse pressure (systolic minus diastolic)

$\mathrm{PH}$ as halftime pressure (the average of systolic and diastolic pressure)

CVP as central venous pressure

$t_{p}$ as time to peak from the diastolic point

$t_{h}$ as time from diastolic point to halftime point

$\mathrm{T}$ the cardiac period or cycle length

$\mathrm{PH}^{\prime}$ as $\mathrm{PH}$ minus CVP

Mean systemic perfusion pressure (mean aortic pressure minus CVP) over the whole cardiac cycle, which is proportional to mean flow or cardiac output, is the area under the pressure pulse curve, divided by its base, or

$$
\overline{\mathrm{P}}_{\mathrm{T}}^{\prime}=\frac{1}{\mathrm{~T}}\left[\mathrm{PH}^{\prime} \cdot \mathrm{t}_{\mathrm{p}}+\left(\mathrm{PH}^{\prime}+\frac{1}{4} \mathrm{PP}\right)\left(\mathrm{t}_{\mathrm{h}}-\mathrm{t}_{\mathrm{p}}\right)+\left(\mathrm{PH}^{\prime}-\frac{1}{4} \mathrm{PP}\right)\left(\mathrm{T}-\mathrm{t}_{\mathrm{h}}\right)\right] .
$$

The corresponding mean systemic perfusion pressure during the halftime interval from 0 to $t_{h}$ is

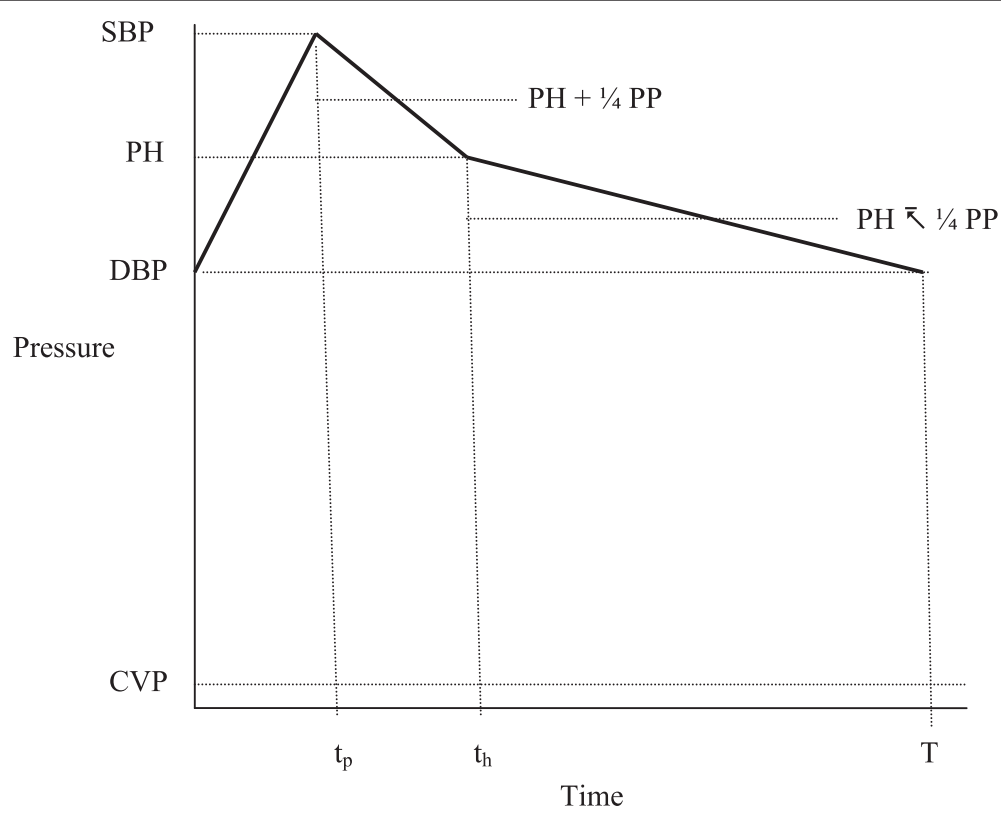

Figure 7 Piecewise linear approximation to a blood pressure waveform with significant points and levels. 


$$
\overline{\mathrm{P}}_{\mathrm{t}_{\mathrm{h}}}{ }^{\prime}=\frac{1}{\mathrm{t}_{\mathrm{h}}}\left[\mathrm{PH} \cdot \mathrm{t}_{\mathrm{p}}+\left(\mathrm{PH}+\frac{1}{4} \mathrm{PP}\right)\left(\mathrm{t}_{\mathrm{h}}-\mathrm{t}_{\mathrm{p}}\right)\right] .
$$

Expanding the terms, cancelling, and dividing by $\mathrm{PH}$ ' gives,

$$
\begin{aligned}
& \frac{\overline{\mathrm{P}}_{\mathrm{t}_{\mathrm{h}}}^{\prime}}{\mathrm{PH}^{\prime}}=1+\frac{1}{4} \frac{\mathrm{PP}}{\mathrm{PH}}\left(1-\frac{\mathrm{t}_{\mathrm{p}}}{\mathrm{t}_{\mathrm{h}}}\right), \text { and } \\
& \frac{\overline{\mathrm{P}}_{\mathrm{T}}^{\prime}}{\mathrm{PH}^{\prime}}=1-\frac{1}{4} \frac{\mathrm{PP}}{\mathrm{PH}}\left(1+\frac{\mathrm{t}_{\mathrm{p}}}{\mathrm{T}}-2 \frac{\mathrm{t}_{\mathrm{h}}}{\mathrm{T}}\right) .
\end{aligned}
$$

Equation (28) states that because of the shape of the blood pressure waveform, the mean perfusion pressure during the first part of the pressure pulse is slightly greater than PH' (the average of systolic and diastolic perfusion pressures). Equation (29) states that because of the shape of the blood pressure waveform, the overall mean perfusion pressure is slightly less than the average of systolic and diastolic perfusion pressures. The desired ratio of perfusion during the halftime interval to cardiac output or average perfusion over cycle length, $\mathrm{T}$, is the ratio of Equations (28) and (29) or

$$
\lambda=\frac{1+\frac{1}{4} \frac{\mathrm{PP}}{\mathrm{PH}}\left(1-\frac{\mathrm{t}_{\mathrm{p}}}{\mathrm{t}_{\mathrm{h}}}\right)}{1-\frac{1}{4} \frac{\mathrm{PP}}{\mathrm{PH}}\left(1+\frac{\mathrm{t}_{\mathrm{p}}}{\mathrm{T}}-2 \frac{\mathrm{t}_{\mathrm{h}}}{\mathrm{T}}\right)}
$$

for the piecewise linear approximation. For computation with $\alpha=\frac{1}{4} \frac{\text { SBP-DBP }}{(\mathrm{SBP}+\mathrm{DBP}) / 2-\mathrm{CVP}}$

$$
\lambda=\frac{1+\alpha\left(1-\frac{t_{\mathrm{p}}}{\mathrm{t}_{\mathrm{h}}}\right)}{1-\alpha\left(1+\frac{\mathrm{t}_{\mathrm{p}}}{\mathrm{T}}-2 \frac{\mathrm{t}_{\mathrm{h}}}{\mathrm{T}}\right)} .
$$

For non-invasive estimates the terms $t_{p}$ and $t_{h}$ can be determined from the time domain output of an external pulse pickup. Systolic and diastolic arterial pressures can be determined noninvasively as well by the usual cuff method and CVP by physical examination of the jugular veins.

\section{Appendix 2: systemic circulation model}

Text Figure 3 illustrates a simple, 12-compartment numerical model of the circulatory system, for which numerical values for inertances, resistances, and compliances are determined as follows.

\section{Inertances}

Inertances [24], L, of each segment of the aorta are computed from blood density, $\rho \approx$ $1.03 \mathrm{~g} / \mathrm{ml}$, segment length, $\mathrm{s}$, in $\mathrm{cm}$, and segment internal cross section, $\mathrm{A}$, in $\mathrm{cm}^{2}$ as

$$
\mathrm{L}=\frac{\rho \mathrm{s}}{\mathrm{A}}
$$

in units of $\left(\right.$ dynes $\left./ \mathrm{cm}^{2}\right) /\left(\mathrm{ml} / \mathrm{sec}^{2}\right)$ or

$$
\mathrm{L}=\frac{1}{1333} \frac{\rho \mathrm{s}}{\mathrm{A}}
$$

in units of $\mathrm{mmHg} /\left(\mathrm{ml} / \mathrm{sec}^{2}\right)$, where instantaneous cross sections, A, are computed from segmental volume divided by the fixed segment length. 


\section{Resistances}

Systemic vascular resistance is estimated as normal mean arterial pressure divided by cardiac output or $95 \mathrm{mmHg} /(5 \mathrm{~L} / \mathrm{min})=95 \mathrm{mmHg} /(83.3 \mathrm{ml} / \mathrm{sec})=1.14 \mathrm{mmHg} /(\mathrm{ml} / \mathrm{sec})$ in total. Each of the 9 parallel systemic vascular resistances in text Figure 3 was $10.3 \mathrm{mmHg} /$ $(\mathrm{ml} / \mathrm{sec})$ or 9 times the total resistance.

Segmental resistances to axial blood flow along the aorta, $R_{a 0}$ and $R_{a 2}$ through $R_{a 8}$, are more than three orders of magnitude smaller than corresponding vascular resistances to drainage of blood from the aorta into the lumped venous compartment. These segmental resistances were initially estimated using Poiseuille's law and then increased empirically to provide a physiologically realistic amount of damping of the arterial pulse waveform in the mock circulation. Final values for $R_{a 0}$ and $R_{a 2}$ through $\mathrm{R}_{\mathrm{a} 8}$ were $0.005 \mathrm{mmHg} /(\mathrm{ml} / \mathrm{sec})$ and remained constant for all simulations. These aortic resistances are equal to each other (no tapering unless otherwise specified). In addition, the end resistances $R_{1}$ and $R_{9}$ are further increased to $0.1 \mathrm{mmHg} /(\mathrm{ml} / \mathrm{sec})$ to model the increased resistance of narrowing vessels in the carotid and femoral arterial trees. Similarly, the pump inflow and outflow resistances, $R_{i}$ and $R_{o}$, are taken as small values $=0.01 \mathrm{mmHg} /(\mathrm{ml} / \mathrm{sec})$.

\section{Compliances}

Using $280 \mathrm{msec}$ as a normal ejection time [34], normal compliance of the aorta is estimated as $83.3 \mathrm{ml} / 40 \mathrm{mmHg}$ multiplied by $\left(1-\mathrm{t}_{\mathrm{e}} / \mathrm{T}\right)$ (text equation $\left.(5)\right)$ or $2.08 *(1-0.28 / 0.75)=$ $1.3 \mathrm{ml} / \mathrm{mmHg}$. For ten equal aortic segments (no tapering) the compliance of each is $0.13 \mathrm{ml} / \mathrm{mmHg}$ normally. Total venous compliance is much larger than aortic compliance and is taken as $10 \mathrm{ml} / \mathrm{mmHg}$. A nominal value for diastolic pump compliance is taken as $60 \mathrm{ml} / 5 \mathrm{mmHg}=12 \mathrm{ml} / \mathrm{mmHg}$ or stroke volume divided by the difference between endsystolic and end-diastolic pressure in the left ventricle.

\section{Vascular dimensions}

For this initial model the length of each aortic segment is taken as $5 \mathrm{~cm}$ and the radius of the aorta is taken (uniformly, unless otherwise specified) as $1.5 \mathrm{~cm}$. The initial volume of the venous reservoir is $2000 \mathrm{ml}$. The initial volume of the heart pump in an arrested circulation is modeled as $200 \mathrm{ml}$.

\section{Pump function}

To make the model go an external, squeezing pressure, $\mathrm{P}_{\text {ext }}(\mathrm{t})$, is applied to the pump compartment having a half sinusoidal waveform, namely

$$
\mathrm{P}_{\text {ext }}(\mathrm{t})=\mathrm{P}_{\max } \cdot \max (0, \sin (\omega \mathrm{t}))
$$

where $\mathrm{P}_{\max }$ is the peak applied pressure. To create a range of stroke volumes in the model $\mathrm{P}_{\max }$ was varied from 25 to $175 \mathrm{mmHg}$.

Pump inflow, $\mathrm{i}_{\mathrm{i}}$, represents ventricular filling. Pump inflow is given by the expression

$$
\mathrm{i}_{\mathrm{i}}=\max \left(0, \frac{\mathrm{P}_{\mathrm{v}}-\mathrm{P}_{\mathrm{p}}}{\mathrm{R}_{\mathrm{i}}}\right) .
$$


Pump output flow, $\mathrm{i}_{\mathrm{o}}$, represents ventricular ejection.

$$
\mathrm{i}_{\mathrm{o}}=\max \left(0, \frac{\mathrm{P}_{\mathrm{p}}-\mathrm{P}_{\mathrm{a} 0}}{\mathrm{R}_{\mathrm{o}}}\right) \text {. }
$$

Here the $\max ()$ functions simulate the effects of the inflow and outflow valves, permitting one-way flow only through the pump.

During a discrete time step, $\Delta \mathrm{t}$, the changes in internal pump volume and internal pump pressure are given by

$$
\Delta \mathrm{V}_{\text {pump }}=\left(\mathrm{i}_{\mathrm{i}}-\mathrm{i}_{\mathrm{o}}\right) \Delta \mathrm{t}
$$

and, using the derivative of external pump pressure in Equation (34),

$$
\begin{aligned}
& \Delta \mathrm{P}_{\text {pump }}=\frac{\Delta \mathrm{V}_{\text {pump }}}{\mathrm{C}_{\text {pump }}}+\mathrm{P}_{\max } \omega \cos (\omega \mathrm{t}) \Delta \mathrm{t}, \text { if } \sin (\omega \mathrm{t})>0 \\
& \text { and } \\
& \Delta \mathrm{P}_{\text {pump }}=\frac{\Delta \mathrm{V}_{\text {pump }}}{\mathrm{C}_{\text {pump }}}, \text { if } \sin (\omega \mathrm{t}) \leq 0 .
\end{aligned}
$$

The cosine function in (38) represents the time derivative of $\mathrm{P}_{\text {ext }}(\mathrm{t})$. Instantaneous pump volume and instantaneous pump pressure as functions of time are determined by numerical integration of expression (37) and expression (38).

\section{Segmental flows}

As shown in text Figure 3, the first aortic segment, indexed a0, represents the ascending aorta, Segment a1 represents the brachiocephalic arteries, and segment a2 represents the aortic arch. Thus flow proceeds from the left ventricle into the ascending aorta (a)), then to the aortic arch (a2), and splits between the brachiocephalic vessels (a1) and the descending thoracic aorta (a3), with flow continuing down the aorta to segment a9. At each time step in the simulation the segmental flows are computed using Ohm's law as

$$
\begin{aligned}
& \mathrm{i}_{\mathrm{a} 0}=\frac{\mathrm{P}_{\mathrm{a} 0}-\mathrm{L}_{0} \frac{\mathrm{di}_{\mathrm{a} 0}}{\mathrm{dt}}-\mathrm{P}_{\mathrm{a} 2}}{\mathrm{R}_{\mathrm{a} 0}}, \\
& \mathrm{i}_{\mathrm{a} 1}=\frac{\mathrm{P}_{\mathrm{a} 2}-\mathrm{L}_{1} \frac{\mathrm{di}_{\mathrm{a} 1}}{\mathrm{dt}}-\mathrm{P}_{\mathrm{a} 1}}{\mathrm{R}_{\mathrm{a} 1}}, \\
& \mathrm{i}_{\mathrm{a} 2}=\frac{\mathrm{P}_{\mathrm{a} 2}-\mathrm{L}_{2} \frac{\mathrm{di}_{2}}{\mathrm{dt}}-\mathrm{P}_{\mathrm{a} 3}}{\mathrm{R}_{\mathrm{a} 2}}, \\
& \mathrm{i}_{\mathrm{a} 3}=\frac{\mathrm{P}_{\mathrm{a} 3}-\mathrm{L}_{3} \frac{\mathrm{di}_{\mathrm{i} 3}}{\mathrm{dt}}-\mathrm{P}_{\mathrm{a} 4}}{\mathrm{R}_{\mathrm{a} 3}},
\end{aligned}
$$

and so on. Systemic flows are given by

$$
\begin{aligned}
& \mathrm{i}_{\mathrm{s} 1}=\frac{\mathrm{P}_{\mathrm{a} 1}-\mathrm{P}_{\mathrm{v}}}{\mathrm{R}_{\mathrm{s} 1}} . \\
& \mathrm{i}_{\mathrm{s} 2}=\frac{\mathrm{P}_{\mathrm{a} 0}-\mathrm{P}_{\mathrm{v}}}{\mathrm{R}_{\mathrm{s} 2}},
\end{aligned}
$$

representing coronary artery blood flow as shown in text Figure 3, and

$$
\mathrm{i}_{\mathrm{s} 3}=\frac{\mathrm{P}_{\mathrm{a} 3}-\mathrm{P}_{\mathrm{v}}}{\mathrm{R}_{\mathrm{s} 3}} .
$$




$$
\mathrm{i}_{\mathrm{s} 4}=\frac{\mathrm{P}_{\mathrm{a} 4}-\mathrm{P}_{\mathrm{v}}}{\mathrm{R}_{\mathrm{s} 4}}, \text { etc. }
$$

\section{Compartmental volume and pressure changes}

At each time step of the simulation the changes in fluid volume and pressure in each compartment are computed next as

$$
\begin{aligned}
& \Delta \mathrm{V}_{\mathrm{a} 0}=\left(\mathrm{i}_{\mathrm{o}}-\mathrm{i}_{\mathrm{a} 0}-\mathrm{i}_{\mathrm{s} 2}\right) \Delta \mathrm{t} ; \quad \Delta \mathrm{P}_{\mathrm{a} 0}=\frac{\Delta \mathrm{V}_{\mathrm{a} 0}}{\mathrm{C}_{\mathrm{a} 0}} ; \\
& \Delta \mathrm{V}_{\mathrm{a} 1}=\left(\mathrm{i}_{\mathrm{a} 1}-\mathrm{i}_{\mathrm{s} 1}\right) \Delta \mathrm{t} ; \Delta \mathrm{P}_{\mathrm{a} 1}=\frac{\Delta \mathrm{V}_{\mathrm{a} 1}}{\mathrm{C}_{\mathrm{a} 1}} ; \\
& \Delta \mathrm{V}_{\mathrm{a} 2}=\left(\mathrm{i}_{\mathrm{a} 0}-\mathrm{i}_{\mathrm{a} 1}-\mathrm{i}_{\mathrm{a} 2}\right) \Delta \mathrm{t} ; \quad \Delta \mathrm{P}_{\mathrm{a} 2}=\frac{\Delta \mathrm{V}_{\mathrm{a} 2}}{\mathrm{C}_{\mathrm{a} 2}} ;
\end{aligned}
$$

in keeping with the plumbing and notation of text Figure 3. Continuing, we have

$$
\begin{aligned}
& \Delta \mathrm{V}_{\mathrm{a} 3}=\left(\mathrm{i}_{\mathrm{a} 2}-\mathrm{i}_{\mathrm{a} 3}-\mathrm{i}_{\mathrm{s} 3}\right) \Delta \mathrm{t} ; \quad \Delta \mathrm{P}_{\mathrm{a} 3}=\frac{\Delta \mathrm{V}_{\mathrm{a} 3}}{\mathrm{C}_{\mathrm{a} 3}} ; \\
& \Delta \mathrm{V}_{\mathrm{a} 4}=\left(\mathrm{i}_{\mathrm{a} 3}-\mathrm{i}_{\mathrm{s} 4}\right) \Delta \mathrm{t} ; \quad \Delta \mathrm{P}_{\mathrm{a} 4}=\frac{\Delta \mathrm{V}_{\mathrm{a} 4}}{\mathrm{C}_{\mathrm{a} 4}},
\end{aligned}
$$

and so on, followed by

$$
\Delta \mathrm{V}_{\mathrm{v}}=\left(\mathrm{i}_{\mathrm{s} 1}+\mathrm{i}_{\mathrm{s} 2}+\mathrm{i}_{\mathrm{s} 3}+\ldots+\mathrm{i}_{\mathrm{s} 9}-\mathrm{i}_{\mathrm{i}}\right) \Delta \mathrm{t} ; \quad \Delta \mathrm{P}_{\mathrm{v}}=\frac{\Delta \mathrm{V}_{\mathrm{v}}}{\mathrm{C}_{\mathrm{v}}}
$$

\section{Flow derivatives}

Flow derivatives, used to calculate inertial effects are then computed from the current and saved last instantaneous flow values, divided by $\Delta \mathrm{t}$, as follows:

$$
\frac{\mathrm{di}_{\mathrm{a} 0}}{\mathrm{dt}}=\frac{\mathrm{i}_{\mathrm{a} 0}-\mathrm{i}_{\mathrm{a} 0 \_ \text {last }}}{\Delta \mathrm{t}} ; \quad \frac{\mathrm{di}_{\mathrm{a} 1}}{\mathrm{dt}}=\frac{\mathrm{i}_{\mathrm{a} 1}-\mathrm{i}_{\mathrm{a} 1 \_ \text {last }}}{\Delta \mathrm{t}} ; \quad \frac{\mathrm{di}_{\mathrm{a} 2}}{\mathrm{dt}}=\frac{\mathrm{i}_{\mathrm{a} 2}-\mathrm{i}_{\mathrm{a} 2 \_ \text {last }}}{\Delta \mathrm{t}} ; \quad \text { etc. }
$$

\section{Computational formulas for instantaneous aortic flows}

Substituting these discretized values (43) into the expressions (39) for flow gives, for example,

$$
\begin{aligned}
& \mathrm{i}_{\mathrm{a} 1}=\frac{\mathrm{P}_{\mathrm{a} 1}-\mathrm{L}_{1}\left(\frac{\mathrm{i}_{\mathrm{a} 1}-\mathrm{i}_{\mathrm{a} 1 \_ \text {last }}}{\Delta \mathrm{t}}\right)-\mathrm{P}_{\mathrm{a} 2}}{\mathrm{R}_{\mathrm{a} 1}} \text { or } \\
& \mathrm{R}_{\mathrm{a} 1} \mathrm{i}_{\mathrm{a} 1}=\mathrm{P}_{\mathrm{a} 1}-\mathrm{L}_{1}\left(\frac{\mathrm{i}_{\mathrm{a} 1}-\mathrm{i}_{\mathrm{a} 1 \_ \text {last }}}{\Delta \mathrm{t}}\right)-\mathrm{P}_{\mathrm{a} 2}, \\
& \left(\mathrm{R}_{\mathrm{a} 1}+\frac{\mathrm{L}_{1}}{\Delta \mathrm{t}}\right) \mathrm{i}_{\mathrm{a} 1}=\mathrm{P}_{\mathrm{a} 1}+\mathrm{L}_{1}\left(\frac{\mathrm{i}_{\mathrm{a} 1 \_ \text {last }}}{\Delta \mathrm{t}}\right)-\mathrm{P}_{\mathrm{a} 2} \text {, so that } \\
& \mathrm{i}_{\mathrm{a} 1}=\frac{\mathrm{P}_{\mathrm{a} 1}+\mathrm{L}_{1}\left(\frac{\mathrm{i}_{\mathrm{a} 1 \text { last }}}{\Delta \mathrm{t}}\right)-\mathrm{P}_{\mathrm{a} 2}}{\mathrm{R}_{\mathrm{a} 1}+\frac{\mathrm{L}_{1}}{\Delta \mathrm{t}}}, \text { etc. }
\end{aligned}
$$

Expressions of this form (45) are used as computational formulas for instantaneous aortic flows $\mathrm{i}_{\mathrm{a} 0}, \mathrm{i}_{\mathrm{a} 1}, \ldots$ through $\mathrm{i}_{\mathrm{a} 8}$. 


\section{Appendix 3: nonlinear compliance correction}

For an aorta having a wall composed of a classical Fungian biomaterial the volume vs. pressure relationship is given by previously derived text Equation (14), namely

$$
\mathrm{V}=\mathrm{V}_{0}+\frac{\mathrm{V}_{0}}{\mathrm{~b}} \times \ln \left(\frac{\mathrm{P}}{\mathrm{P}_{\mathrm{ref}}}+1\right)
$$

where the constant, $b=\frac{V_{0}}{2 C_{\text {ref }} P_{\text {ref }}}$, as previously explained. Here $P_{\text {ref }}$ is a reference pressure, close to normal diastolic pressure, where a standard value of compliance at normal physiologic pressure, $\mathrm{P}_{\text {ref }}$, would be defined in the equation for the nonlinear compliance model. This standard value of dynamic compliance at the reference pressure from Text Equation (16) is $\left(\frac{\mathrm{dV}}{\mathrm{dP}}\right)_{\text {ref }}=\frac{\mathrm{V}_{0}}{2 \mathrm{~b}} \times \frac{1}{\mathrm{P}_{\mathrm{ref}}}=\mathrm{C}_{\text {ref }}$. Hence, the volume versus pressure curve is given by

$$
\mathrm{V}=\mathrm{V}_{0}+2 \mathrm{C}_{\text {ref }} \mathrm{P}_{\text {ref }} \ln \left(\frac{\mathrm{P}}{\mathrm{P}_{\text {ref }}}+1\right),
$$

and the difference in volume between two steady state pressures $P_{1}$ and $P_{2}$ is

$$
\mathrm{V}_{2}-\mathrm{V}_{1}=2 \mathrm{C}_{\text {ref }} \mathrm{P}_{\text {ref }}\left[\ln \left(\frac{\mathrm{P}_{2}}{\mathrm{P}_{\text {ref }}}+1\right)-\ln \left(\frac{\mathrm{P}_{1}}{\mathrm{P}_{\text {ref }}}+1\right)\right]=2 \mathrm{C}_{\text {ref }} \mathrm{P}_{\text {ref }} \ln \left(\frac{\mathrm{P}_{2}+\mathrm{P}_{\text {ref }}}{\mathrm{P}_{1}+\mathrm{P}_{\text {ref }}}\right) .
$$

For the halftime method of text Equation (9) we have $V_{2}-V_{1}=S V\left(1-\lambda \frac{t_{h}}{T}\right)$, which represents the volume of blood added to the aorta during the last left ventricular ejection that still remains within the aorta at halftime, $t_{h}$. Therefore, using the primed variable, SV', to denote the nonlinear condition, and Equation (48) for $V_{1}-V_{2}$, where $V_{1}$ is the halftime aortic volume and $V_{2}$ is the diastolic aortic volume, we have

$$
\mathrm{SV}^{\prime}=\frac{2 \mathrm{C}_{\mathrm{ref}} \mathrm{P}_{\mathrm{ref}}}{1-\lambda \frac{\mathrm{t}_{\mathrm{h}}}{\mathrm{T}}} \ln \left(\frac{(\mathrm{SBP}+\mathrm{DBP}) / 2+\mathrm{P}_{\mathrm{ref}}}{\mathrm{DBP}+\mathrm{P}_{\mathrm{ref}}}\right)
$$

Using pulse wave velocity to estimate compliance at the prevailing diastolic blood pressure, the estimated compliance for the nonlinear compliance model would be

$$
\mathrm{C}_{\mathrm{est}}=\left(\frac{\mathrm{dV}}{\mathrm{dP}}\right)_{\mathrm{DBP}}=2 \mathrm{C}_{\mathrm{ref}} \times \frac{\mathrm{P}_{\mathrm{ref}}}{\mathrm{DBP}+\mathrm{P}_{\mathrm{ref}}},
$$

so that $2 \mathrm{C}_{\text {ref }} \mathrm{P}_{\text {ref }}=\mathrm{C}_{\text {est }}\left(\mathrm{DBP}+\mathrm{P}_{\text {ref }}\right)$ and using Equation (49),

$$
\mathrm{SV}^{\prime}=\frac{\mathrm{C}_{\mathrm{est}}\left(\mathrm{DBP}+\mathrm{P}_{\mathrm{ref}}\right)}{1-\lambda \frac{\mathrm{t}_{\mathrm{h}}}{\mathrm{T}}} \ln \left(\frac{\mathrm{DBP}+\mathrm{PP} / 2+\mathrm{P}_{\text {ref }}}{\mathrm{DBP}+\mathrm{P}_{\text {ref }}}\right) .
$$

The halftime method gives an uncorrected value for stroke volume based on text Equation (9), assuming constant compliance $C_{\text {est }}$, of

$$
\mathrm{SV}=\frac{\mathrm{C}_{\mathrm{est}} \cdot \mathrm{PP}}{2\left(1-\frac{\lambda \mathrm{t}_{\mathrm{h}}}{\mathrm{T}}\right)}
$$

Dividing Equations (51) and (52), the ratio of stroke volume with nonlinear aortic compliance to that calculated assuming constant compliance is 


$$
\frac{\mathrm{SV}^{\prime}}{\mathrm{SV}} \approx \frac{2\left(\mathrm{DBP}+\mathrm{P}_{\mathrm{ref}}\right)}{\mathrm{PP}} \ln \left(\frac{\mathrm{DBP}+\mathrm{PP} / 2+\mathrm{P}_{\mathrm{ref}}}{\mathrm{DBP}+\mathrm{P}_{\text {ref }}}\right) .
$$

Equation (53) gives a small correction for the presence of nonlinearity. Taking the reference pressure $\mathrm{P}_{\text {ref }}$ as $80 \mathrm{mmHg}$ or normal diastolic blood pressure,

$$
\frac{\mathrm{SV}^{\prime}}{\mathrm{SV}}=\frac{2(\mathrm{DBP}+80)}{\mathrm{PP}} \ln \left(1+\frac{\mathrm{PP}}{2(\mathrm{DBP}+80)}\right) .
$$

In the limiting case for very small values of pulse pressure, PP, one can use the series approximation for $\varepsilon<<1$

$$
\begin{aligned}
& \ln (1+\varepsilon) \approx \varepsilon-\frac{1}{2} \varepsilon^{2}=\varepsilon\left(1-\frac{1}{2} \varepsilon\right), \text { so that } \\
& \frac{\mathrm{SV}^{\prime}}{\mathrm{SV}} \approx 1-\frac{1}{4} \frac{\mathrm{PP}}{\mathrm{DBP}+80} .
\end{aligned}
$$

As expected, for extremely small pulses the effect of nonlinearity is negligible. For increasingly larger pulses the correction factor becomes progressively less than unity.

For blood pressure of 120/80 Equation (54) gives 0.942 and Equation (55) gives 0.938. For blood pressure 180/40 Equation (54) gives 0.473 and Equation (55) gives 0.708 . Hence, in general, and especially for higher pulse pressures, one must use the exact logarithmic expression of Equation (54).

\section{Appendix 4: the delta method}

The probable error method or delta method $[30,35]$ may be used to approximate variances of functions of random variables. If $\mathrm{X}$ is a random variable with mean $\mu$ and variance $\sigma^{2}$, the variance $\sigma^{2}(f(X)) \approx \sigma^{2}(X)\left(f^{\prime}(\mu)\right)^{2}$ where $f^{\prime}(X)$ is the first derivative of function $f(X)$ with respect to $X$. To appreciate the approximation one can visualize the function $f(X)$ as a graph with a tangent of slope $\mathrm{f}^{\prime}(\mu)$ at point $(\mu, \mathrm{f}(\mu))$. By deduction from such a graph, it follows that the standard deviation of $f(X)$ is approximately $\mathrm{f}^{\prime}(\mu)$ times the standard deviation of $\mathrm{X}$, as long as $\mathrm{f}^{\prime}(\mathrm{X})$ does not change greatly over the range of $\mathrm{X}$. For the case of $\mathrm{f}$ $(X)=\ln (X)$, the delta method gives $\sigma^{2}(\ln (X)) \approx \frac{1}{\mu^{2}} \sigma^{2}(X)$.

Competing interests

The author declares that he has no competing interests.

\section{Authors' contributions}

$\mathrm{CB}$ is the only author and is responsible for all aspects of the research and the intellectual and technical content of the manuscript. He reads and approved the final manuscript.

Received: 9 June 2014 Accepted: 16 September 2014

Published: 19 September 2014

\section{References}

1. Mimoz O, Rauss A, Rekik N, Brun-Buisson C, Lemaire F, Brochard L: Pulmonary artery catheterization in critically ill patients: a prospective analysis of outcome changes associated with catheter-prompted changes in therapy. Crit Care Med 1994, 22:573-579.

2. Kurita T, Morita K, Kato S, Kikura M, Horie M, Ikeda K: Comparison of the accuracy of the lithium dilution technique with the thermodilution technique for measurement of cardiac output. Br J Anaesth 1997, 79:770-775.

3. Connors AF Jr, Speroff T, Dawson NV, Thomas C, Harrell FE Jr, Wagner D, Desbiens N, Goldman L, Wu AW, Califf RM, Fulkerson WJ, Viadillet H, Broste S, BGellamy P, Lynn J, Knaus WA: The effectiveness of right heart catheterization in the initial care of critically ill patients. SUPPORT Investigators. JAMA 1996, 276:889-897.

4. Harvey S, Harrison DA, Singer M, Ashcroft J, Jones CM, Elbourne D, Brampton W, Williams D, Young D, Rowan K: Assessment of the clinical effectiveness of pulmonary artery catheters in management of patients in intensive care (PAC-Man): a randomised controlled trial. Lancet 2005, 366:472-477. 
5. Harvey S, Stevens K, Harrison D, Young D, Brampton W, McCabe C, Singer M, Rowan K: An evaluation of the clinical and cost-effectiveness of pulmonary artery catheters in patient management in intensive care: a systematic review and a randomised controlled trial. Health Technol Assess 2006, 10:iii-iv. ix-xi, 1-133.

6. Geerts BF, Aarts LP, Jansen JR: Methods in pharmacology: measurement of cardiac output. Br J Clin Pharmacol 2011, 71:316-330.

7. Rajzer MW, Wojciechowska W, Klocek M, Palka I, Brzozowska-Kiszka M, Kawecka-Jaszcz K: Comparison of aortic pulse wave velocity measured by three techniques: complior, SphygmoCor and arteriograph. J Hypertens 2008, 26:2001-2007.

8. Bhatt S, Ghazale H, Dogra VS: Sonographic evaluation of the abdominal aorta. Ultrasound Clinics 2007, 2:437-453.

9. Remington JW, Noback CR, Hamilton WF, Gold JJ: Volume elasticity characteristics of the human aorta and prediction of the stroke volume from the pressure pulse. Am J Physiol 1948, 153:298-308.

10. Ferguson JJ, Julius S, Randall OS: Stroke volume-pulse pressure relationships in borderline hypertension: a possible indicator of decreased arterial compliance. J Hypertens Supp/ 1984, 2:S397-S399.

11. Chemla D, Hebert JL, Coirault C, Zamani K, Suard I, Colin P, Lecarpentier Y: Total arterial compliance estimated by stroke volume-to-aortic pulse pressure ratio in humans. Am J Physiol 1998, 274:H500-H505.

12. Jansen JR, Wesseling KH, Settels JJ, Schreuder JJ: Continuous cardiac output monitoring by pulse contour during cardiac surgery. Eur Heart J 1990, 11(I):26-32.

13. de Simone G, Roman MJ, Koren MJ, Mensah GA, Ganau A, Devereux RB: Stroke volume/pulse pressure ratio and cardiovascular risk in arterial hypertension. Hypertension 1999, 33:800-805.

14. Posey J, Geddes L: Measurement of the modulus of elasticity of the arterial wall. Cardiovasc Res Cent Bull 1973, 11:83-103.

15. Bramwell J, Hill A: The velocity of the pulse wave in man. Proc R Soc Lond Ser B 1922, 93:298-306

16. Huntsman LL, Stewart DK, Barnes SR, Franklin SB, Colocousis JS, Hessel EA: Noninvasive Doppler determination of cardiac output in man. Clinical validation. Circulation 1983, 67:593-602.

17. Ciaccio EJ, Drzewiecki GM: Tonometric arterial pulse sensor with noise cancellation. IEEE Trans Biomed Eng 2008, 55:2388-2396.

18. Kemmotsu O, Ueda M, Otsuka H, Yamamura T, Okamura A, Ishikawa T, Winter DC, Eckerle JS: Blood pressure measurement by arterial tonometry in controlled hypotension. Anesth Analg 1991, 73:54-58

19. Sato T, Nishinaga M, Kawamoto A, Ozawa T, Takatsuji H: Accuracy of a continuous blood pressure monitor based on arterial tonometry. Hypertension 1993, 21:866-874.

20. Voges I, Jerosch-Herold M, Hedderich J, Pardun E, Hart C, Gabbert DD, Hansen JH, Petko C, Kramer HH, Rickers C: Normal values of aortic dimensions, distensibility, and pulse wave velocity in children and young adults: a cross-sectional study. J Cardiov Magn Reson 2012, 14:77.

21. Blacher J, Asmar R, Djane S, London GM, Safar ME: Aortic pulse wave velocity as a marker of cardiovascular risk in hypertensive patients. Hypertension 1999, 33:1111-1117.

22. Asmar R, Benetos A, Topouchian J, Laurent P, Pannier B, Brisac AM, Target R, Levy BI: Assessment of arterial distensibility by automatic pulse wave velocity measurement. Validation and clinical application studies. Hypertension 1995, 26:485-490.

23. Jezewski J, Roj D, Wrobel J, Horoba K: A novel technique for fetal heart rate estimation from Doppler ultrasound signal. Biomed Eng Online 2011, 10:92.

24. Babbs CF, Weaver JC, Ralston SH, Geddes LA: Cardiac, thoracic, and abdominal pump mechanisms in cardiopulmonary resuscitation: studies in an electrical model of the circulation. Am J Emerg Med 1984, 2:299-308

25. Drzewiecki G, Field S, Moubarak I, Li JK: Vessel growth and collapsible pressure-area relationship. Am J Physiol 1997, 273:H2030-H2043.

26. Fung YC: Biomechanics: Mechanical Properties of Living Tissues. New York: Springer-Verlag; 1981.

27. Geddes LA, Voelz MH, Babbs CF, Bourland JD, Tacker WA: Pulse transit time as an indicator of arterial blood pressure. Psychophysiology 1981, 18:71-74.

28. Babbs CF: Anterior-posterior impedance cardiography: a new approach to accurate, non-invasive monitoring of cardiac function. Cardiovasc Eng 2010, 10:52-65.

29. Alhashemi JA, Cecconi M, Hofer CK: Cardiac output monitoring: an integrative perspective. Crit Care 2011, 15:214.

30. Crumpler TB, Yoe JH: Chemical Computations and Errors. New York: John Wiley \& Sons, Inc:; 1940.

31. Critchley LA, Critchley JA: A meta-analysis of studies using bias and precision statistics to compare cardiac output measurement techniques. J Clin Monit Comput 1999, 15:85-91.

32. Stevens K, McCabe C, Jones C, Ashcroft J, Harvey S, Rowan K: The incremental cost effectiveness of withdrawing pulmonary artery catheters from routine use in critical care. Applied Health Econ Health Pol 2005, 4:257-264

33. Marik PE: Noninvasive cardiac output monitors: a state-of the-art review. J Cardiothorac Vasc Anesth 2013, 27:121-134.

34. Lance VQ, Spodick DH: Heart rate-left ventricular ejection time relations. Variations during postural change and cardiovascular challenges. Br Heart J 1976, 38:1332-1338.

35. Oehlert GW: A note on the delta method. Am Stat 1992, 46:27-29.

doi:10.1186/1475-925X-13-137

Cite this article as: Babbs: Noninvasive measurement of cardiac stroke volume using pulse wave velocity and aortic dimensions: a simulation study. BioMedical Engineering OnLine 2014 13:137. 